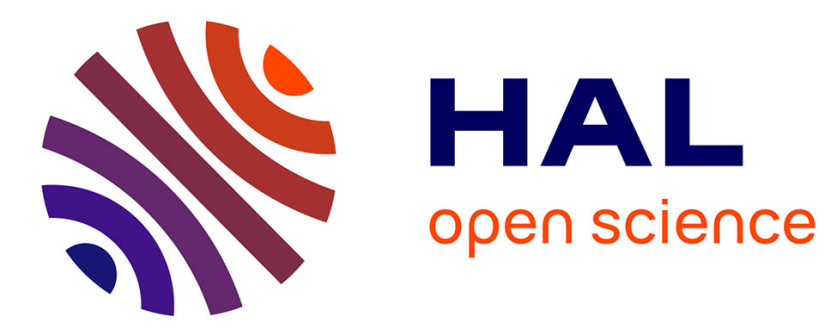

\title{
Integration of Environmental Impact Estimation in System Architecture \& Supplier Identification
}

Yun Ye, Marija Jankovic, Gül E. Okudan Kremer, Bernard Yannou, Yann Leroy, Jean-Claude Bocquet

\section{- To cite this version:}

Yun Ye, Marija Jankovic, Gül E. Okudan Kremer, Bernard Yannou, Yann Leroy, et al.. Integration of Environmental Impact Estimation in System Architecture \& Supplier Identification. Research in Engineering Design, 2016, 27 (2), pp.117-140. 10.1007/s00163-015-0208-x . hal-01272663

\section{HAL Id: hal-01272663 https://hal.science/hal-01272663}

Submitted on 20 Sep 2016

HAL is a multi-disciplinary open access archive for the deposit and dissemination of scientific research documents, whether they are published or not. The documents may come from teaching and research institutions in France or abroad, or from public or private research centers.
L'archive ouverte pluridisciplinaire HAL, est destinée au dépôt et à la diffusion de documents scientifiques de niveau recherche, publiés ou non, émanant des établissements d'enseignement et de recherche français ou étrangers, des laboratoires publics ou privés. 
Ye Y., Jankavic M., Kremer G., Yannou B., Leray Y., Bocquet J.-C., "Integration of Enviranmental Impact Estimation in System Architecture \& Supplier Identification", Research in Engineering Design vol., 2015, dai: 10.1007/s00163-015-0208-x.

\title{
Integration of Environmental Impact Estimation in System Architecture \& Supplier Identification
}

\author{
Yun YE $^{1}$, Marija JANKOVIC ${ }^{1}$, Gül E. KREMER ${ }^{2}$, Bernard YANNOU ${ }^{1}$, \\ Yann LEROY $^{1}$, Jean-Claude BOCQUET ${ }^{1}$ \\ ${ }^{1}$ Laboratoire Genie Industriel, Ecole Centrale Paris, Chatenay-Malabry, France \\ ${ }^{2}$ Engineering Design and Industrial Engineering, The Pennsylvania State University, \\ University Park, PA, USA
}

yun.ye@ecp.fr, marija.jankovic@ecp.fr, gkremer@psu.edu, bernard.yannou@ecp.fr, yann.leroy@ecp.fr, jean-claude.bocquet@ecp.fr

\begin{abstract}
With the emergence of environmental legislations in many countries, the importance placed upon environmental protection has been raised to a new level, especially for industrial activities. Considering environmental issues as early as possible, starting with the design stage, is expected in order to better manage and diminish adverse environmental impact. Commensurate progress has been made in method/tool development for use in environmental impact estimation; however, very few of these methods allow integrating this estimation early in the design process - a critical point of deciding for potential product concepts and suppliers. In this paper, we propose a tool that integrates environmental impact estimation into architecture and supplier identification, in order to conjointly consider requirements satisfaction as well as uncertainty due to new module and new supplier integration. This tool is developed to support OEM (Original Equipment Manufacturer) decision-making in the context of an extended enterprise. A case study is presented to illustrate a plausible implementation.
\end{abstract}

Keywords: environmental impact estimation, architecture generation, supplier identification, early design stages

\section{Introduction}

Current studies have shown that becoming environment-friendly not only enables companies to create new business but also lower costs (Nidumolu, Prahalad, \& Rangaswami, 2009). Studies (Drumwright 1994) show that $75 \%$ of consumers say that their purchasing decisions are affected by a company's environmental reputation, and $80 \%$ say that they would pay more for environment-friendlier goods. At the same time, because of the emergence of environmental legislations (e.g., The Waste Electrical \& Electronic Equipment Directive (WEEE) of European Union), some non-environment-friendly products may now be more expensive to dispose (Lamming \& Hampson, 1996). Being "green and competitive" is increasingly adopted as the win-win position (Porter \& Linde, 1995). Taking into account overall environmental impact has been recognized as important also in the OEM (Original Equipment Manufacturers) context (Bhamra et al., 1999). However, current environmental impact estimation methods lack capabilities for considering new customer requirements, new modules (such as the engine or the battery within a vehicle), and new suppliers simultaneously. In order to address this gap, we propose ASIT-E (Figure 1) that is developed based on the Architecture \& Supplier Identification Method and Tool (ASIT) for overall environmental impact estimation during early design. The aim of this approach is to use this capability to further filter system 


\section{Ye Y., Jankavic M., Kremer G., Yannou B., Leray Y., Bocquet J.-โ., "Integration of Environmental Impact Estimation in System Architecture \& Supplier Identification", Research in Engineering Design vol., 2015, dai: 10.1007/s00163-015-0208-x.}

architectures and focus on those considered more environmental friendly while at the same time considering overall system performance. Three thresholds (i.e., environmental impact, requirements satisfaction, and project uncertainty) are used to filter architectures and suppliers in order to provide a list of qualified candidates for further negotiation and selection.

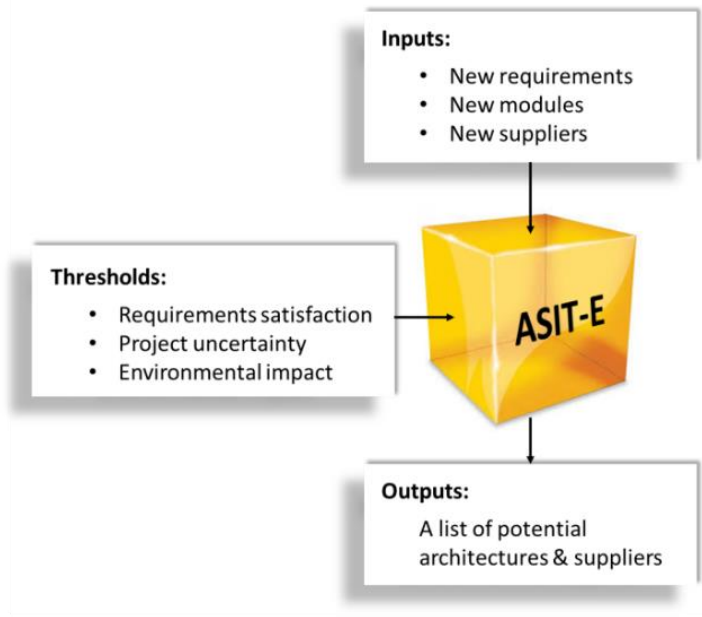

Fig. 1 Overview of ASIT-E

In section 2, relevant literature pertaining to environmental directives and indicators is discussed. Section 3 provides details of the proposed method; powertrain design case illustrates the proposed method in Section 4. Section 5 compares ASIT-E implementation results to those of a method that does not take environmental impacts into account. We discuss the results and potential managerial implications (Section 6). In the end, overall conclusions are discussed.

\section{Background}

Grisel \& Duranthon (2001) underline the need to use lifecycle method and multi-criteria method in order to estimate global environmental impacts. Considering entire product lifecycle avoids shifting environmental impact downstream (i.e., lowering of environmental impact in one step may exacerbate the problem in another step), while using multi-criteria methods helps to consider impacts from all sources. The ASIT-E considers the entire lifecycle of a product and uses environmental indicators to reflect possible environmental problems in each lifecycle phase. Specifically, the aim of this work is to create a framework/method to use a sample of identified indicators, rather than providing a list of globally applicable indicators. Indeed existent studies already pointed out that indicators strongly vary across industries and companies, and it is not appropriate to use one list of indicators for all situations (Lee \& Billington, 1992; Bhutta, 2003). Here we discuss different environmental indicators and identify those that are adapted to the automotive industry in particular with regard to existing data in early design.

\subsection{Consideration of environmental issues in architecture and supplier identification}

In recent years, the consideration of environmental issues in supplier selection has attracted a lot of attention (Lloyd 1994). Humphreys et al. (2003) identified quantitative and qualitative environmental criteria that fall into 7 environmental categories, using which suppliers are selected. Handfield, Walton, Sroufe \& Melnyk (2002) identified the top 10 criteria for supplier environmental performance, and the top 10 most easily assessed criteria based on interviews with companies. They propose to use Analytical Hierarchy Process (AHP) multi-criteria decision method to assess suppliers along environmental dimensions. Bai \& Sarkis (2010) propose to integrate the "triple-bottom-line" selection factors (i.e., economic, environmental as well as social factors) for supplier selection decision-making under uncertainty. 


\section{Ye Y., Jankavic M., Kremer G., Yannau B., Leray Y., Bacquet J.-C., "Integration of Enviranmental Impact Estimation in System Architecture \& Supplier Identification", Research in Engineering Design vol., 2015, dai: 10.1007/s00163-015-0208-x.}

To the best of our knowledge, very few methods have been proposed that consider system architecture and supplier selection.

We found only three research works that are closely related. Two of these, the works of Krikke, BloemhofRuwaard \& Van Wassenhove (2003) and Chung, Kremer \& Wysk (2014) focus on selecting modular structures of products to optimize product lifecycle performances in a closed-loop supply chain environment. In these two studies, product components are fixed, and authors seek to group these components in different ways to form modules in order to optimize environmental as well as other performance measures. The third study, carried out by Taghaboni-Dutta, Trappey \& Trappey (2010), proposed a platform where suppliers can upload their green parts, and OEMs can find environmental friendly alternatives for their products more easily. These approaches are based upon evaluation of existing technologies and components. However, early design phases are characterized by uncertainties and consideration of new possibilities, involving new technologies, new modules, and new suppliers. The necessity to innovate enabling evaluation of new modules or suppliers is essential.

\subsection{Research focus: Product lifecycle phases}

The European Union's Waste Framework Directive (European Commission, 2008) requires that the EU member states apply the following waste ${ }^{1}$ management activities in a priority order: 1) prevention ${ }^{2}, 2$ ) preparing for re-use ${ }^{3}, 3$ ) recycling $\left.{ }^{4}, 4\right)$ other recovery ${ }^{5}$, and 5) disposal ${ }^{6}$. The closed-loop production where EOL (end-of-life) products are re-used (at the part or product level) or recycled (at the material level) has been attracting attention both in academia and industry. The closed-loop supply chain is the form of supply chain often used along with closed-loop production, where collection points and reverse-feed centres are built to collect and process EOL products (Georgiadis \& Besiou, 2010). This closed-loop supply chain framework has been used as the context for the ASIT-E approach (Figure 2). However, ASIT-E supports customization through lifecycle phases; OEMs can choose to use a subset of the lifecycle phases proposed in Fig. 2, or adding other phases according to their domain of activity. Ideally modules are produced by suppliers using recycled materials, to be transported to the OEM. Assembly is carried out in OEM facilities, and transported to the distribution centre, and then to customers. The EOL products are collected at collection points and sent to reverse-feed centres, where reusable high quality modules are separated for minor repair, and then reused in new products. Non-reusable parts are either recycled for material, sent for other recovery, or disposed.

${ }^{1}$ Waste: Any substance or object which the holder discards or intends or is required to discard (European Commission, 2008).

${ }^{2}$ Prevention: Measures taken before a substance, material or product has become waste, that reduce the quantity of waste, the adverse impacts of the generated waste on the environment and human health, or the content of harmful substances in materials and products (European Commission, 2008).

${ }^{3}$ Re-use: Any operation by which products or components that are not waste are used again for the same purpose for which they were conceived (European Commission, 2008).

${ }^{4}$ Recycling: Any recovery operation by which waste materials are reprocessed into products, materials or substances whether for the original or other purposes (European Commission, 2008).

${ }^{5}$ Recovery: Any operation the principal result of which is waste serving a useful purpose by replacing other materials which would otherwise have been used to fulfil a particular function, or waste being prepared to fulfil that function, in the plant or in the wider economy (European Commission, 2008).

${ }^{6}$ Disposal: Any operation which is not recovery even where the operation has as a secondary consequence of reclamation of substances or energy (European Commission, 2008). 


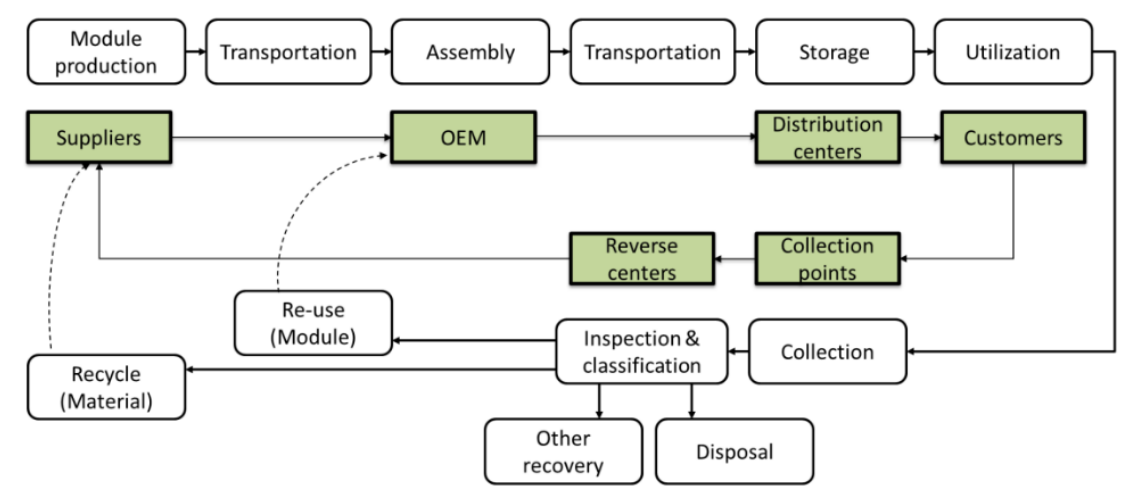

Fig. 2 Product lifecycle phases considered in ASIT-E (Özkır \& Başlıgil, 2012)

\subsection{Environmental directives \& indicators}

The selection of environmental indicators depends greatly on OEM's particular needs, e.g., product category, local legislations, strategy. Here we discuss a set of indicators, but one should not consider this as a final set. OEM's should adapt this set to their own needs, and ASIT-E provides flexibility to add or remove indicators. In order to consider potential environmental impact sources, both product architecture and supplier related environmental indicators should be considered. The supplier related indicators highlight environmental impact generated in the phases of manufacturing and supplier-OEM transportation, while the architecture related indicators consider the characteristic of a particular product concept (e.g., toxic material used), and its potential performance during utilization (e.g., consumption of electricity).

Regarding supplier related environmental indicators, we adopt indicators from the work of Handfield et al. (2002). Normally, environmental performance of suppliers is evaluated by the procurement department once the product concept is decided. However, in ASIT-E, the purpose is to weed out unqualified suppliers at the very early stages of product development, in parallel with concept definition. Therefore, we seek to identify the most important and easily accessible environmental indicators. In the work of Handfield et al. (2002), six indicators are considered both important and easily accessible: (1) ISO 14001 certified, (2) use of ozone depleting substances, (3) use of EPA 17 hazardous materials, (4) environmental friendly packaging, (5) use of recycled material, and (6) public disclosure of environmental record. We regroup "use of ozone depleting substances" and "use of EPA 17 hazardous materials" into module related indicators since they are design/product specific. We consider the following four indicators in ASIT-E as supplier related indicators: 1) ISO 14001 certified, 2) Environmental friendly packaging, 3) Use of recycled material and 4) Public disclosure of environmental record.

In order to avoid environmental legislation violations by the final product, we abstracted indicators from legislations that the product must conform to. Although many governments have introduced environmental regulations and directives, we mainly focus on the European Union, and three specific directives that are most related to complex system development:

1) Waste Electrical \& Electronic Equipment Directive (WEEE);

2) Restriction of Hazardous Substances Directive (RoHS);

3) European Eco-design Directive (Erp).

The WEEE (European Commission, 2014c) is the European Community directive on Waste Electrical and Electronic Equipment, which sets collection, recycling and recovery targets for all types of electrical goods. This directive requires that, starting from 2016, the minimum collection rate shall be $45 \%$ of the total weight of WEEE collected in a given year. The percentage is calculated based on the average weight of EEE (Electrical and Electronic Equipment) placed on the market in the three preceding years. The recovery rate and the recycle rate are also defined for each category of EEE for different periods.

The RoHS (Restriction of Hazardous Substances Directive (European Commission, 2014b), newest version: 2011/65/EU) restricts the use of six hazardous materials in the manufacture of all types of electrical and electronic equipment. This directive restricts the use of the six substances with maximum concentration values tolerated by weight in homogeneous materials (see Fig. 3). 
Ye Y., Jankavic M., Kremer G., Yannou B., Leray Y., Bacquet J.-C., "Integration of Environmental Impact Estimation in System Architecture \& Supplier Identification", Research in Engineering Design vol., 2015, dai: 10.1007/s00163-015-0208-x.

\begin{tabular}{l|lc} 
& Material & $\begin{array}{c}\text { Maximum concentration rate } \\
\text { (by weight) }\end{array}$ \\
\hline 1 & Lead $(\mathrm{Pb})$ & $0.10 \%$ \\
2 & Mercury $(\mathrm{Hg})$ & $0.10 \%$ \\
3 & Cadmium $(\mathrm{Cd})$ & $0.01 \%$ \\
4 & Hexavalent chromium $\left(\mathrm{Cr}^{6+}\right.$ ) & $0.10 \%$ \\
5 & Polybrominated biphenyls (PBB) & $0.10 \%$ \\
6 & Polybrominated diphenyl ether (PBDE) & $0.10 \%$
\end{tabular}

Fig. 3 Restricted Materials by RoHS

The European Eco-design Directive (Directive 2009/125/EC (European Commission, 2014a)) aims at establishing a framework for setting eco-design requirements for "energy-related products". While the directive's primary aim is to reduce energy use, it also aims at enforcing other environmental considerations, including: materials use, polluting emissions, waste issues, and recyclability.

Using the literature on these three directives, we identified the most important indicators (shown in Fig. 4). For example, we choose to focus on electricity consumption for energy consumption, and consider $\mathrm{CO}_{2}$ emission for polluting emissions. The definition of "scarce material" is adopted from the list of "critical raw materials" defined by European commission (The ad-hoc Working Group, 2010). The final waste is not considered in ASIT-E, mainly because it can be covered by material recoverability and the use of hazardous materials; the recoverability is inversely proportional to the final waste, and if no hazardous material is used, the final waste is not going to be hazardous either. The indicators used in ASIT-E are customizable.

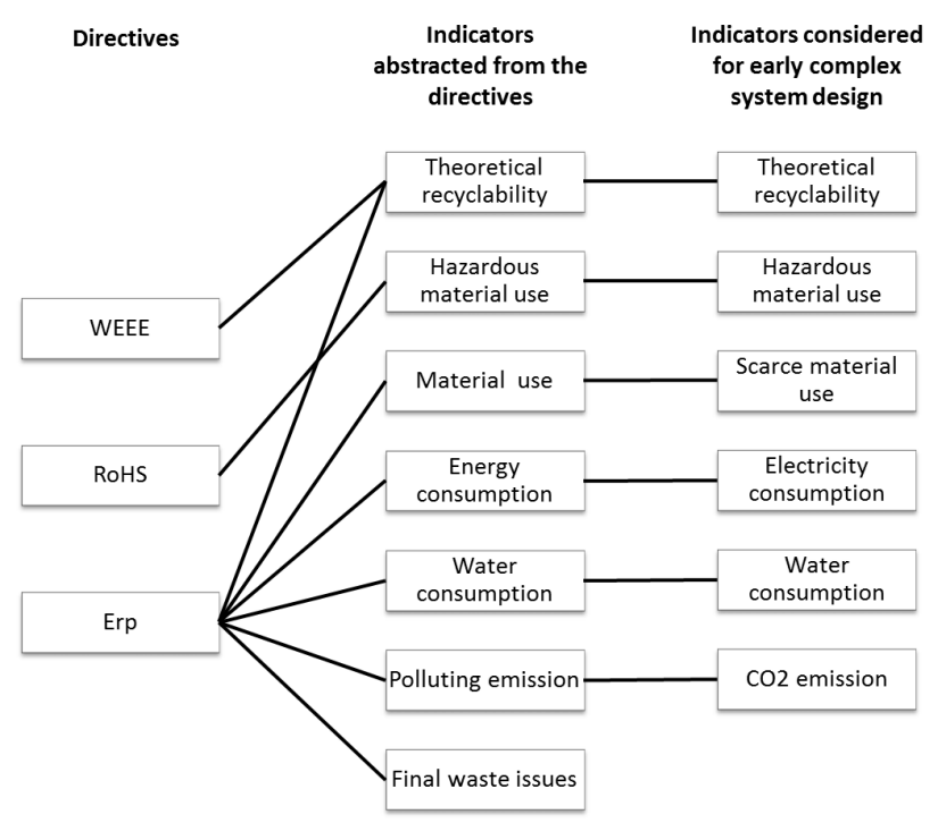

Fig. 4 Indicator identification from directives

We regroup the indicators related to architectures and suppliers into three categories (shown in Fig. 5) in order to use them in different steps within ASIT-E. The first group of indicators relates to modules, while the second group relates to environmental capability of suppliers. The third group of indicators relates to both architectures and suppliers and the entire lifecycle of the product. For example, the electricity consumption can occur during production, transportation, product use, and disposal. In ASIT-E, we use the first and second group of indicators to filter out modules and suppliers, in order to avoid unqualified candidates; then, use the remaining modules to generate architectures. Finally, indicators from the third group are estimated for the entire lifecycle for each product architecture. 
Ye Y., Jankovic M., Kremer G., Yannau B., Leray Y., Bocquet J.-C., "Integration of Environmental Impact Estimation in System Architecture \& Supplier Identification", Research in Engineering Design vol., 2015, dai: 10.1007/s00163-015-0208-x.

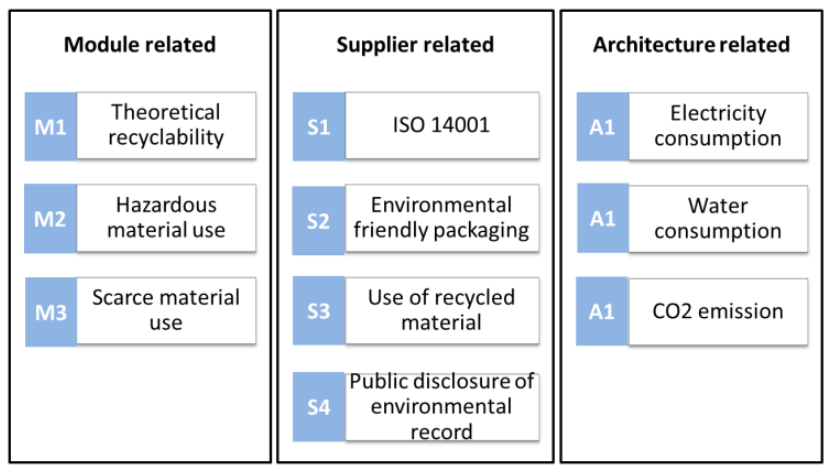

Fig. 5 Environmental indicators used in ASIT-E

\section{Environmental impact estimation in system architecture and supplier identification: proposition of ASIT-E}

In order to propose a suitable decision support tool for companies to successfully integrate environmental benefits into their business goals and plans (Hallstedt, Ny, Robèrt, \& Broman 2010), we propose ASIT-E (Figure 6): a tool that integrates environmental impacts estimation into ASIT originally proposed by (Ye, Jankovic, Kremer, \& Bocquet 2014). Steps highlighted with a dark background are specific to ASIT-E (not included in ASIT).This approach starts from estimation of new requirements satisfaction by existing products; identifies requirements that are not satisfied; and finds new modules (possibly from new suppliers) that can potentially better satisfy the requirements. The potential module set is filtered by the module- and supplier-related environmental indicators in order to weed out the inadequate modules and suppliers. All possible architectures are then regenerated using qualified modules. Then, the requirements satisfaction and the overall uncertainty of architectures (including uncertainty of modules to attain certain performances due to new technology integration, compatibility between modules, and supplier performance uncertainty) are estimated; architectures are filtered by requirements satisfaction and uncertainty thresholds. Finally, the environmental impact of the remaining architectures is estimated; and the environmental impact threshold is used to filter the architectures once again. A list of qualified architectures and suppliers is generated as candidates for further negotiation. 
Ye Y., Jankavic M., Kremer G., Yannau B., Leray Y., Bacquet J.-C., "Integration of Enviranmental Impact Estimation in System Architecture \& Supplier Identification", Research in Engineering Design vol., 2015, dai: 10.1007/s00163-015-0208-x.

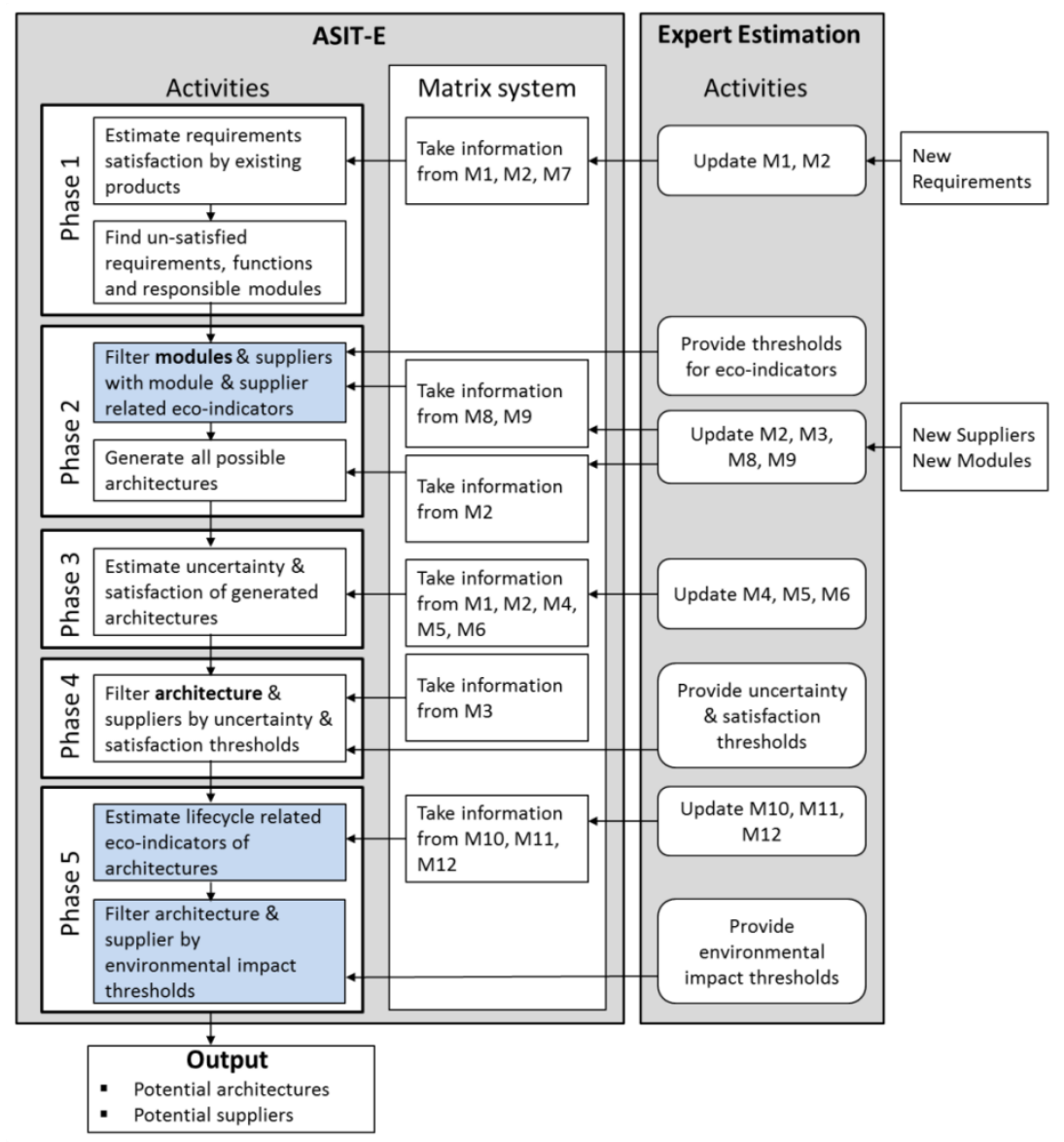

Fig. 6 Overview of ASIT-E

ASIT-E uses a matrix system (shown in Fig. 7) as database. To reduce uncertainty and consequently, risk, complex systems are rarely designed from scratch. Project documents regarding requirements, functions, and modules usually exist. This information is commonly captured and reused using software such as DOORS. However, different types of data are rarely stored in one place. The idea behind ASIT and ASITE databases is to store critical, high-level data from previous projects within one matrix system, to facilitate information organization, acquisition, and utilization.

ASIT has seven matrices in its matrix system: matrices 1, 2, and 3 represent requirements, function, module relations; matrices 4, 5 and 6 represent uncertainty information: the compatibility between modules (4), uncertainty of modules (5), and uncertainty of suppliers' capabilities (6). Matrix 7 represents composition of existing products. In addition to these seven matrices, ASIT-E has five more matrices (8-12). Matrices 8 and 9 represent module related and supplier related environmental indicators, respectively; while matrices 10, 11, and 12 represent architectures' performance in lifecycle related environmental indicators (i.e., electricity consumption, water consumption, and $\mathrm{CO}_{2}$ emission). 


\section{Ye Y., Jankavic M., Kremer G., Yannou B., Leray Y., Bacquet J.-C., "Integration of Environmental Impact Estimation in System Architecture \& Supplier Identification", Research in Engineering Design vol., 2015, dai: 10.1007/s00163-015-0208-x.}

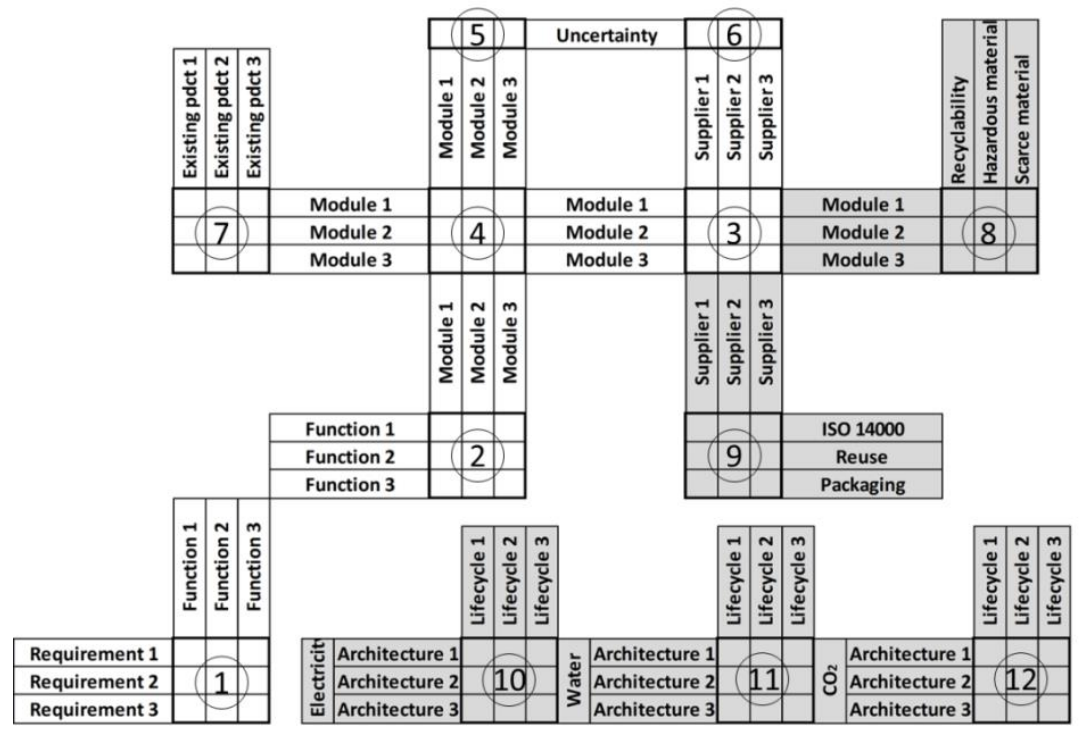

Fig. 7 Matrix system used in ASIT-E

When starting a new project, usually the project manager organizes a 1-3 day workshop to discuss innovation integration, different system architectures, as well as other constrains. These workshops are attended by different domain experts in order to capture overall system knowledge. The ASIT-E is conceived for use during this kind of a workshop, and the matrix system can be filled in by the group of experts attending the workshop, and using data from existing products as well as information provided by suppliers. When filling the matrix system, experts use predefined linguistic terms of satisfaction levels and probabilities as shown in Fig. 8 and Fig. 9. The definition of the levels can be different from company to company in order to reflect different needs. It is important that the experts share the same definition for the scale system before estimation. When estimating satisfaction levels, " 0 " is used to represent that "the module does not provide the function".

\begin{tabular}{lc}
\hline \multicolumn{1}{c}{ Linguistic terms } & Satisfaction level \\
\hline Very inadequate solution & 1 \\
Weak solution & 2 \\
Tolerable solution & 3 \\
Adequate solution & 4 \\
Satisfactory solution & 5 \\
Good solution with few drawbacks & 6 \\
Good solution & 7 \\
Very good solution & 8 \\
Solution better than requirements & 9 \\
Ideal solution & 10 \\
\hline
\end{tabular}

Fig. 8 Satisfaction levels (Fiod-Neto \& Back, 1994) 
Ye Y., Jankavic M., Kгеmer G., Yannau B., Leray Y., Bacquet J.-C., "Integration of Enviranmental Impact Estimation in System Architecture \& Supplier Identification", Research in Engineering Design vol., 2015, dai: 10.1007/s00163-115-0208-X.

\begin{tabular}{lc}
\hline \multicolumn{1}{c}{ Linguistic terms } & Probability \\
\hline Impossible & 0 \\
Nearly impossible & 0.1 \\
Very unlikely & 0.2 \\
Quite unlikely & 0.3 \\
Possible & 0.4 \\
Even chance & 0.5 \\
Better than even chance & 0.6 \\
Quite likely & 0.7 \\
Very likely & 0.8 \\
Nearly certain & 0.9 \\
Certain & 1 \\
\hline
\end{tabular}

Fig. 9 Probabilities

In the next section, a powertrain design case is used to illustrate the utilization of ASIT-E.

\section{The Powertrain Design Case}

\subsection{Case description}

We use the design of a plug-in hybrid electric powertrain to show utilization of ASIT-E. A powertrain is a system of mechanical parts in a vehicle that first provides energy, and then converts it in order to propel the vehicle. The main objective in designing a powertrain is to provide adequate propulsion with minimal use of fuel while emitting minimal hazardous by-products or pollutants. This case study involves three types of powertrains: the traditional gas powertrain, the hybrid electric powertrain, and the plug-in electric powertrain. An example of the plug-in hybrid electric powertrain is shown in Fig. 10.

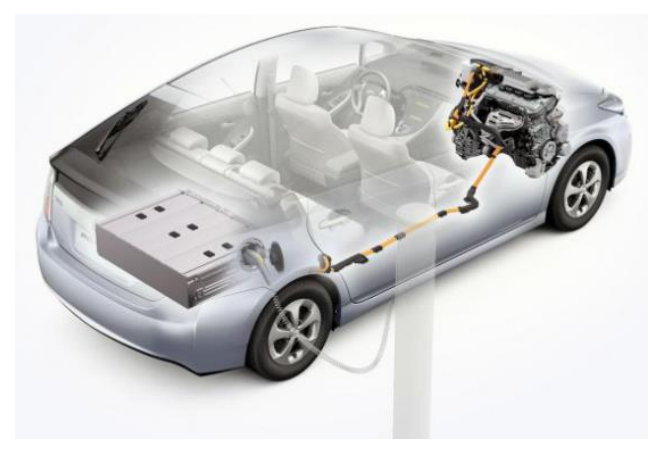

Fig. 10 Toyota Prius Plug-in Hybrid Electric Powertrain (Beissmann, 2011)

Due to the increasing demand for higher fuel efficiency and lower $\mathrm{CO}_{2}$ emission, the OEM plans to design a new plug-in hybrid electric powertrain for their motor vehicle to better satisfy market needs. The new powertrain needs to satisfy mainly six requirements (requirements 1-4 are adapted from Michelena \& Papalambros, (1995)): (1) Corporate Average Fuel Economy (CAFE) standard: Europe currently requires 54 miles per UK gallon, violation of this standard results in proportional fines, (2) Acceleration time: This directly relates to customer perceived performance, (3) Cruising velocity at gradient: Relates to the speed at which vehicles can climb a 6\% gradient in fourth gear, (4) Greenhouse gas emissions: This measure shows a vehicle's impact on climate change in terms of the amount of greenhouse gases (e.g., $\left.\mathrm{CO}_{2}\right)$ it emits, (5) Rechargeable by external electric power, and (6) Long All-Electric Range (AER): This indicates the driving range of the vehicle using only power from its electric battery pack, in charge-depleting mode. 


\section{Ye Y., Jankavic M., Kremer G., Yannou B., Leray Y., Bacquet J.-C., "Integration of Environmental Impact Estimation in System Architecture \& Supplier Identification", Research in Engineering Design vol., 2015, dai: 10.1007/s00163-015-0208-x.}

\subsection{Phase I-Requirements satisfaction by existing products}

Complex systems are rarely designed from scratch. OEMs usually try to improve their existing products to satisfy new requirements. However, it is usually not clear which module should be improved and for which function of the module. In ASIT, we proposed to first estimate how well OEM's existing products satisfy the new requirements. By using matrix mapping, the unsatisfied requirements can be traced to unsatisfied functions, and finally to responsible modules. Thereby, OEMs know exactly which modules and functions to improve.

Using the matrix system, experts can choose adequate existing requirements from the list; and if necessary, add new requirements to it. Based on the requirement-function relations stored in matrix $\mathrm{M}_{1}$, the existing functions related to defined requirements can be found. The requirements - function relations for new requirements are provided by experts using percentages (representing the contribution of a function to a requirement), as shown in Fig. 11. Experts only need to fill out the white area of the matrix, because the other information is filled automatically using information from existing products.

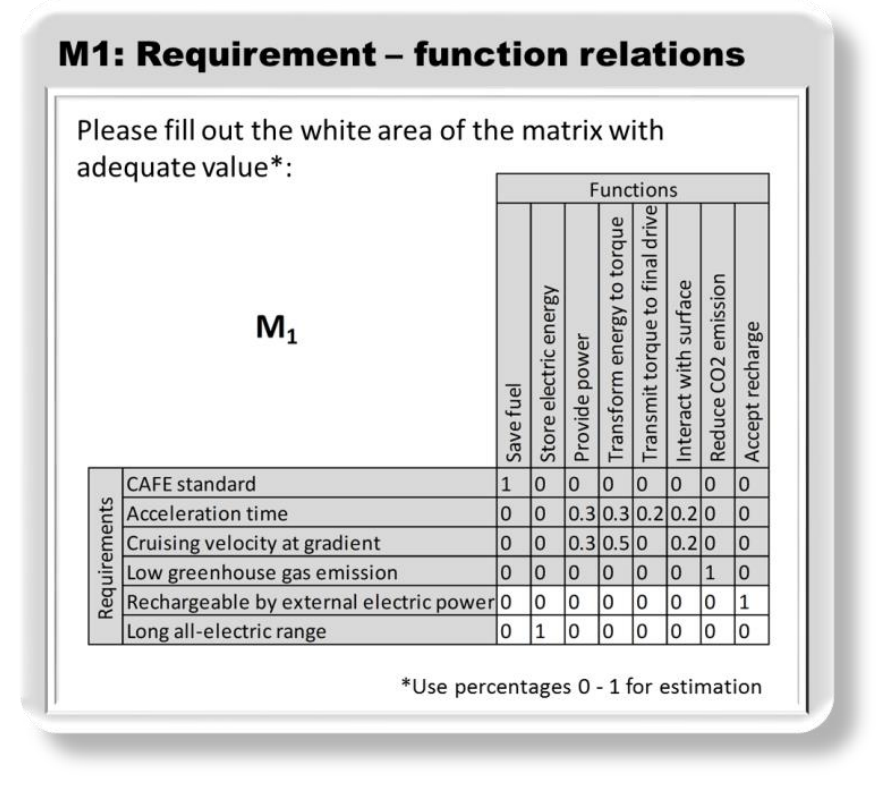

Fig. 11 Requirement - function relations

Experts also discuss module types that are needed based on functions, and relations between new functions and module types. How well each module satisfies the new functions is also provided by experts, using satisfaction levels, as shown in Fig. 12. 
Ye Y., Jankavic M., Kremer G., Yannou B., Leray Y., Bacquet J.-C., "Integration of Enviranmental Impact Estimation in System Architecture \& Supplier Identification", Research in Engineering Design vol., 2015, dai: 10.1007/s00163-015-0208-X.

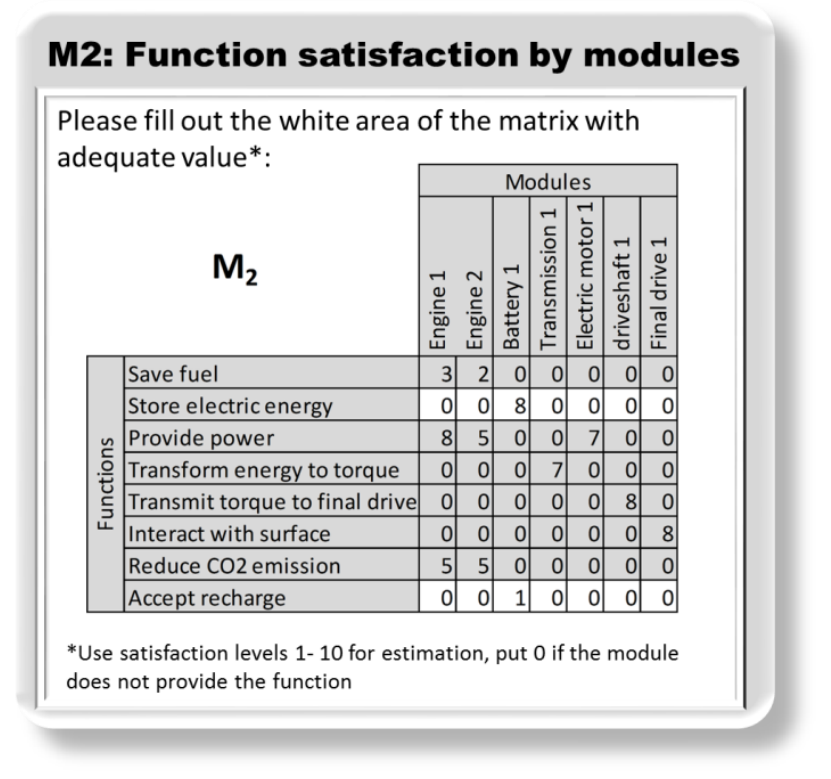

Fig. 12 Function satisfaction level by modules

The OEM has successfully developed two types of powertrains in the past (i.e., a traditional gas powertrain, and a hybrid electric powertrain), which are used as foundations for the new powertrain development. $\mathbf{M}_{7}$ (Fig. 13) shows the composition of the two powertrains. We assume that this information is already stored in the database, as it is updated after each project.

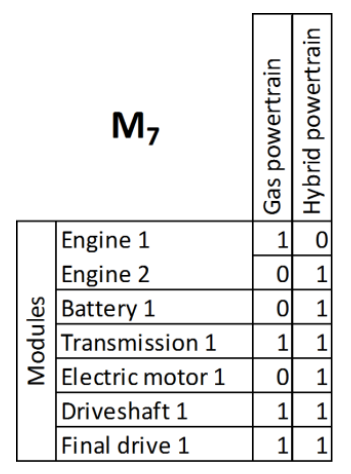

Fig. 13 Composition of existing powertrains

By using $\mathrm{M}_{1}, \mathrm{M}_{2}$, and $\mathrm{M}_{7}$, ASIT-E can calculate how well the existing products satisfy the requirements. ASIT-E converts "how module satisfies functions (in $\mathrm{M}_{2}$ )" to "how an existing product satisfies functions" using product composition in $\mathrm{M}_{7}$. The satisfaction of a function by a product is defined as the average of satisfaction levels of the modules in the product that are designed to fulfill the function. For example, the hybrid powertrain has two modules (engine 2 and electric motor 1 ) fulfilling the function "provide power". Therefore, if the "engine 1" satisfies the "provide power" function at level 5 and "electric motor 1" satisfies the function at level 7, then the gas powertrain satisfies this function at level 6 (average of 5 and 7), as shown in matrix $\mathrm{M}_{\text {fun-arch }}$ (Fig. 14). 
Ye Y., Jankavic M., Kгemer G., Yannau B., Leray Y., Bacquet J.-C., "Integration of Enviranmental Impact Estimation in System Architecture \& Supplier Identification", Research in Engineering Design vol., 2015, dai: 10.1007/s00163-015-0208-x.

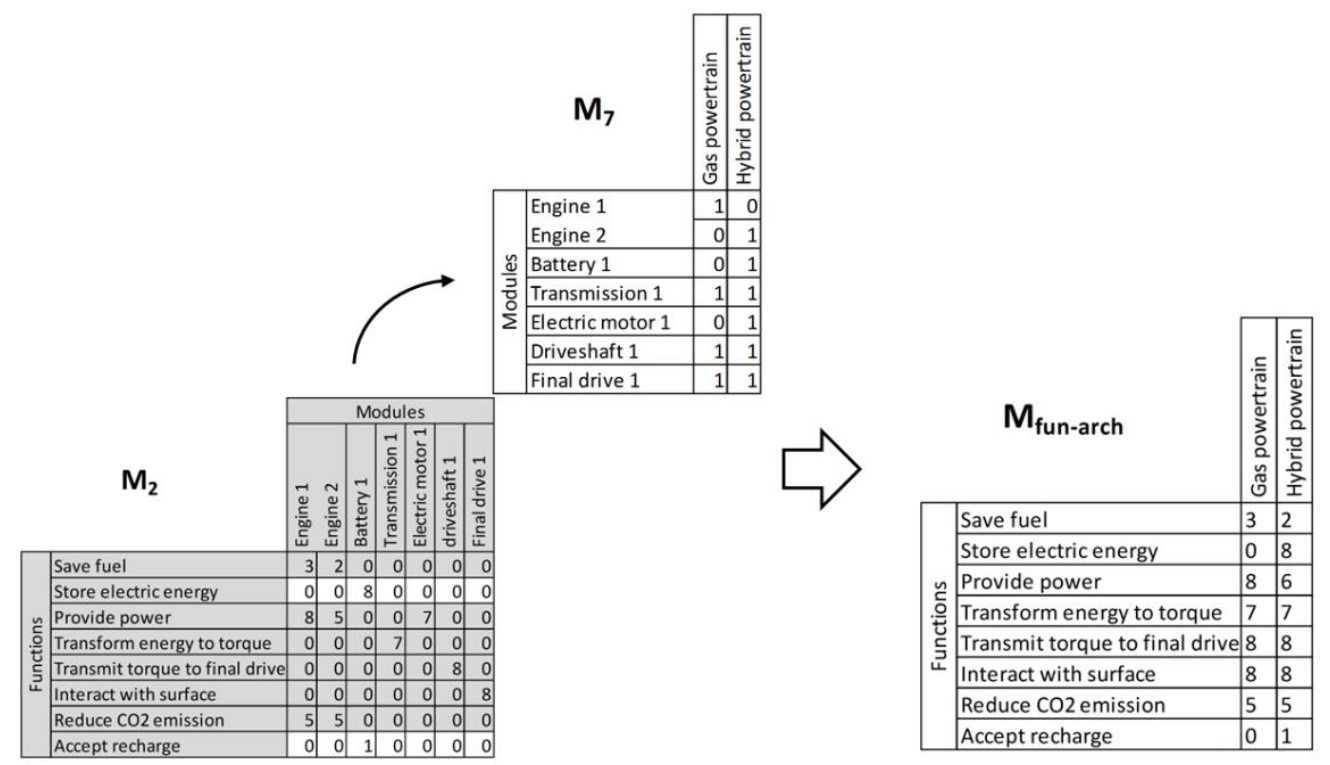

Fig. 14 Function satisfaction level by existing products

Then, the requirement - function relations $\left(M_{1}\right)$ are used to propagate the satisfaction of functions to the satisfaction of requirements (Figure 15):

$$
M_{\text {req-arch }}=M_{1} \times M_{\text {fun-arch }}
$$

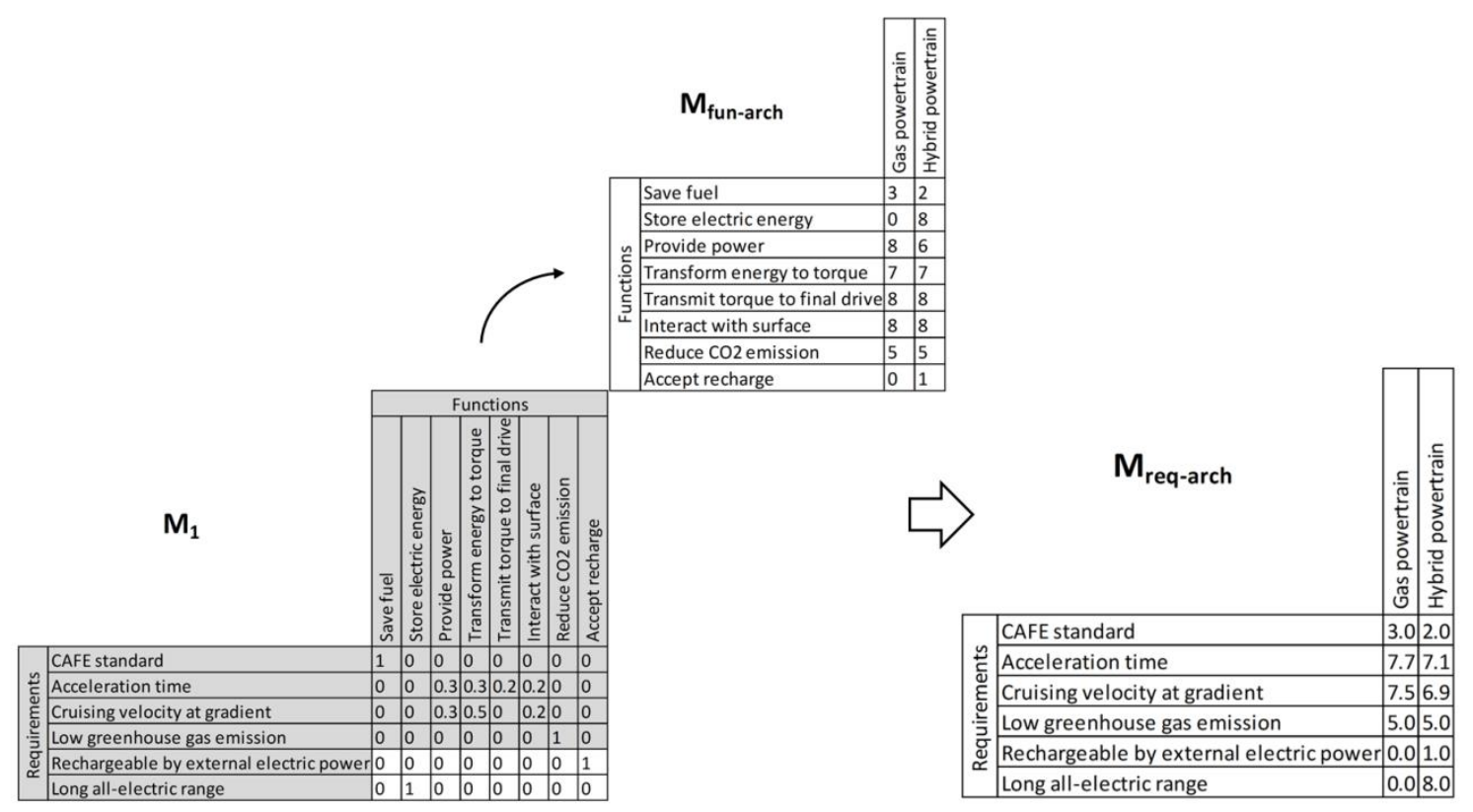

Fig. 15 Requirement satisfaction of existing products

Since level 5 is defined as the default "satisfactory solution", the requirements "CAFE standard", "rechargeable by external electric power", and "long all-electric range" are unsatisfied. Figure 15 shows that the requirement "CAFE standard" is related to the function "save fuel", the requirement "rechargeable by external electric power" is related to the function "accept recharge", and the requirement "long allelectric range" is related to the function "store electric energy". Using $\mathrm{M}_{2}$, it can be seen that the satisfaction 


\section{Ye Y., Jankavic M., Kremer G., Yannau B., Leray Y., Bocquet J.-С., "Integration of Enviranmental Impact Estimation in System Architecture \& Supplier Identification", Research in Engineering Design vol., 2015, dai: 10.1007/s00163-015-0208-x.}

of these three functions depends only on the engine and the battery. Therefore, new engines and batteries, which can potentially satisfy these functions, need to be developed.

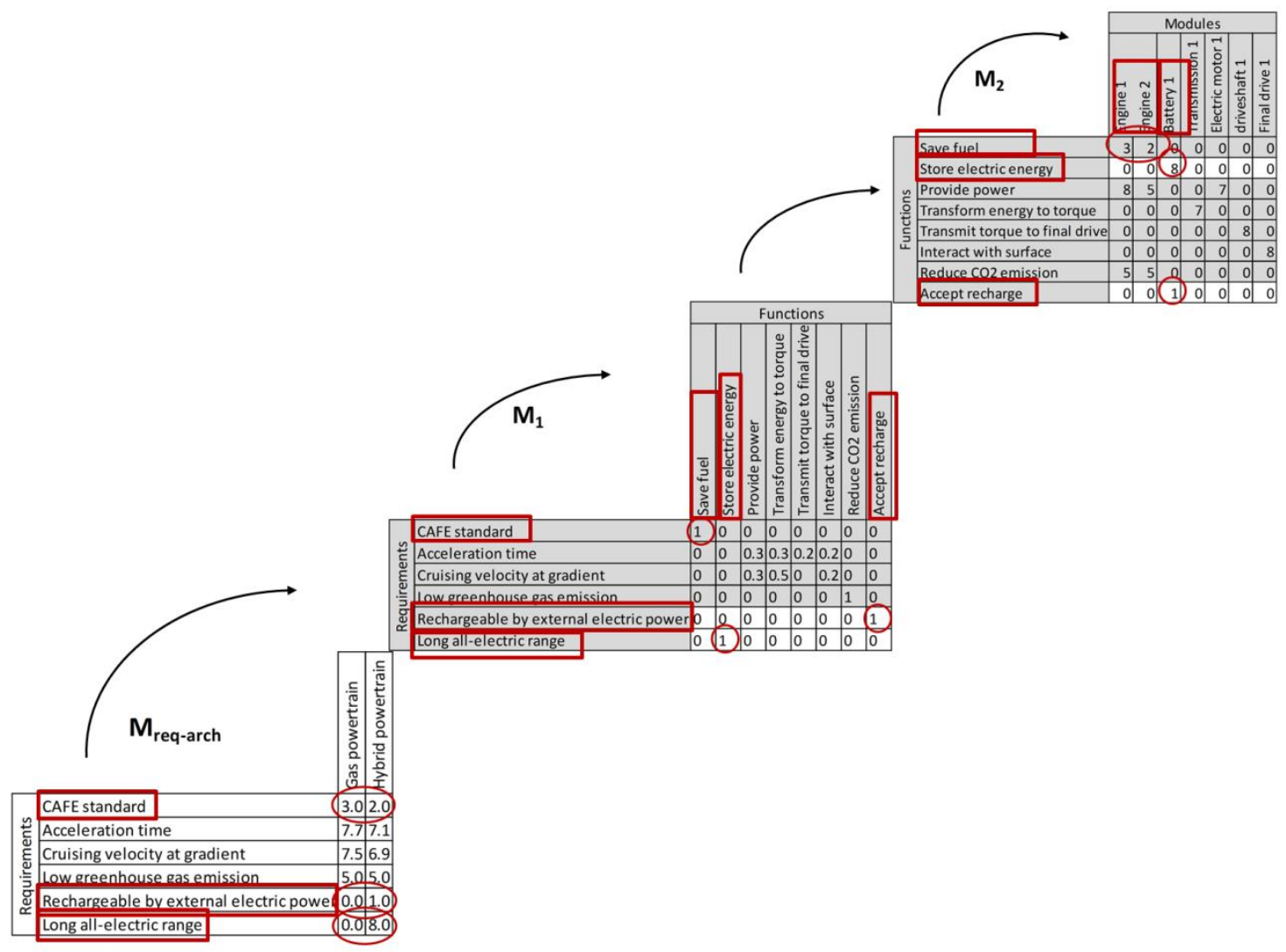

Fig. 16 Matrix mapping for finding responsible modules

\subsection{Phase II - Module, supplier filtering \& solution generation}

The objective of this phase is three-fold: (1) find/propose potential new solutions by experts for unsatisfied functions, (2) use module related environmental indicators (theoretical recyclability, hazardous material use, and scarce material use) and supplier related environmental indicators (ISO 14001, environmental friendly packaging, use of recycled material, and public disclosure of environmental record) to filter solutions, and (3) generate all possible architectures with integration of the new modules that meet the standards.

After searching for new modules provided either by new or existing suppliers, four new engines (engine $\# 3$, \#4, \#5, and \#6) and five new batteries (batteries \#2, \#3, \#4, \#5, and \#6) are found. The simplified descriptions of these modules are shown in Fig. 17.

\begin{tabular}{cl|ll} 
Supplier & Module & \multicolumn{1}{|c}{ Main Material } & \multicolumn{1}{c}{ Fuel (for engine) } \\
\hline$\# 1$ & Engine 1 & Steel & Diesel \\
$\# 1$ & Engine 2 & Steel & Gasoline \\
$\# 1$ & Engine 3 & Aluminum & Gasoline \\
$\# 2$ & Engine 4 & Steel & Hydrogen \\
$\# 3$ & Engine 5 & Steel & Hydrogen \\
$\# 4$ & Engine 6 & Steel & CNG (Compressed Nature Gas) \\
$\# 5$ & Battery 1 & NiMH (Nickel Metal Hybride) & \\
$\# 6$ & Battery 2 & LiFePO & \\
$\# 6$ & Battery 3 & Lithium-ion & \\
$\# 7$ & Battery 4 & Lithium-ion & \\
$\# 7$ & Battery 5 & Nickel-Cadmium & \\
$\# 8$ & Battery 6 & Carbon Nanotube Electrode Lithium
\end{tabular}




\section{Ye Y., Jankavic M., Kremer G., Yannou B., Leray Y., Bacquet J.-C.., "Integration of Environmental Impact Estimation in System Architecture \& Supplier Identification", Research in Engineering Design vol., 2015, dai: 10.1007/s00163-015-0208-x.}

\section{Fig. 17 Engines and Batteries}

The module-related indicators and supplier-related indicators are used to control the environmental impact of these modules and their suppliers, before integrating these modules into architectures. Ideally, the estimation of these two types of indicators is based on information provided by suppliers. However, the quality of information provided by suppliers varies a lot. Therefore, if the information from suppliers is not complete, OEMs can rely on expert estimation. In the worst case, if experts are not able to provide estimations of a certain indicator, OEM can consider other indicators. Sometimes, for the same indicator, different OEMs may have different interpretations. For example, for "environmental friendly packaging", OEM can consider the recyclability of packaging material, or the mass of packing material per mass of the module. In this work, we focus on illustrating the overall implementation of the ASIT-E structure, rather than proposing a detailed estimation method for each indicator. The estimations of module-related and supplier-related environmental indicators are shown in Fig. 18 and Fig. 19, respectively.

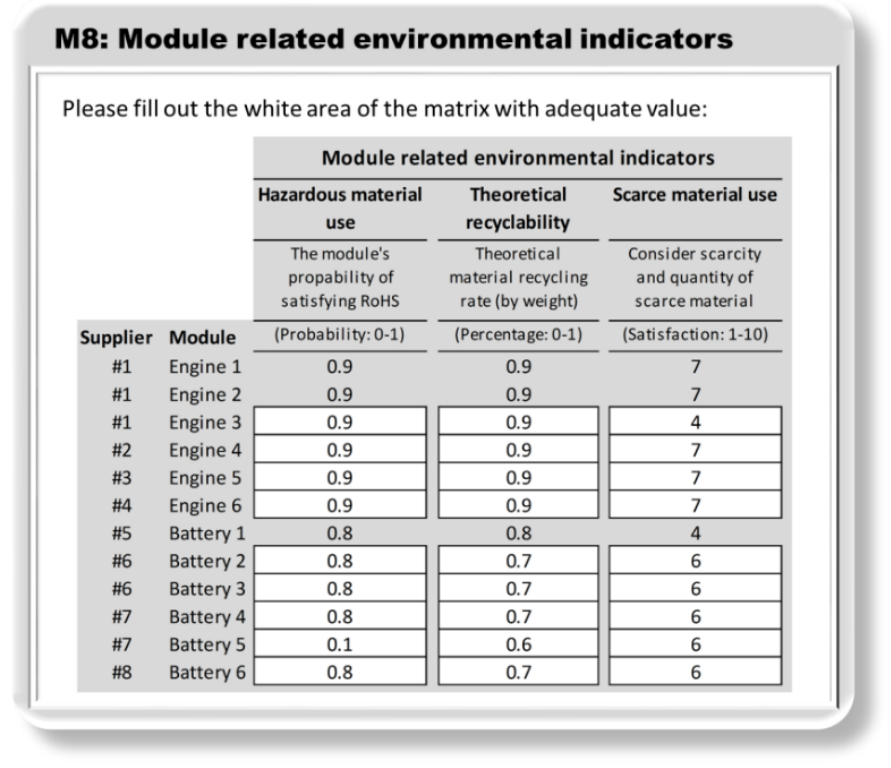

Fig. 18 Estimation of module related environmental indicators

\section{M9: Supplier related environmental indicators}

Please fill out the white area of the matrix with adequate value:

\begin{tabular}{|c|c|c|c|c|c|}
\hline & & \multicolumn{4}{|c|}{ Supplier related environmental indicators } \\
\hline & & ISO 14001 & $\begin{array}{l}\text { Use of recycled } \\
\text { material }\end{array}$ & $\begin{array}{c}\text { Environmental } \\
\text { friendly packaging }\end{array}$ & $\begin{array}{l}\text { Public disclosure of } \\
\text { environmental record }\end{array}$ \\
\hline & & $\begin{array}{l}\text { Possesion of } \\
\text { ISO14001 } \\
\text { certification }\end{array}$ & $\begin{array}{l}\text { Capability of using } \\
\text { recycled material }\end{array}$ & $\begin{array}{l}\text { Recycling rate of } \\
\text { packaging }\end{array}$ & $\begin{array}{l}\text { Disclosed information } \\
\text { comparing to desired } \\
\text { information }\end{array}$ \\
\hline Supplier & Module & (Satisfaction: 1 or 10 ) & (Satisfaction: 1-10) & (Percentage: 0-1) & (Ratio: 0-1) \\
\hline$\# 1$ & Engine 1 & & & & \\
\hline$\# 1$ & Engine 2 & 10 & 8 & 0.7 & 0.5 \\
\hline \#1 & Engine 3 & & & & \\
\hline \#2 & Engine 4 & 10 & 7 & 0.8 & 0.6 \\
\hline \#3 & Engine 5 & 10 & 2 & 0.7 & 0.2 \\
\hline \#4 & Engine 6 & 10 & 6 & 0.7 & 0.7 \\
\hline \#5 & Battery 1 & 10 & 8 & 0.7 & 0.4 \\
\hline $\begin{array}{l}\# 6 \\
\# 6\end{array}$ & $\begin{array}{l}\text { Battery } 2 \\
\text { Battery } 3\end{array}$ & 10 & 7 & 0.6 & 0.6 \\
\hline $\begin{array}{l}\# 7 \\
\# 7\end{array}$ & $\begin{array}{l}\text { Battery } 4 \\
\text { Battery } 5\end{array}$ & 1 & 7 & 0.4 & 0.3 \\
\hline \#8 & Battery 6 & 10 & 6 & 0.8 & 0.6 \\
\hline
\end{tabular}




\section{Ye Y., Jankavic M., Kremer G., Yannou B., Leray Y., Bacquet J.-C., "Integration of Environmental Impact Estimation in System Architecture \& Supplier Identification", Research in Engineering Design vol., 2015, dai: 10.1007/s00163-015-0208-x.}

Fig. 19 Estimation of supplier related environmental indicators

In order to filter the modules and suppliers, experts are asked to provide thresholds for environmental indicators (see Fig. 20). The thresholds for some of the indicators come from environmental directives (e.g., hazardous material use and theoretical material recyclability). For others, the threshold setting is for the purpose of getting an appropriate number of candidates when exploring the design space, and can be one of the decision parameters for experts.

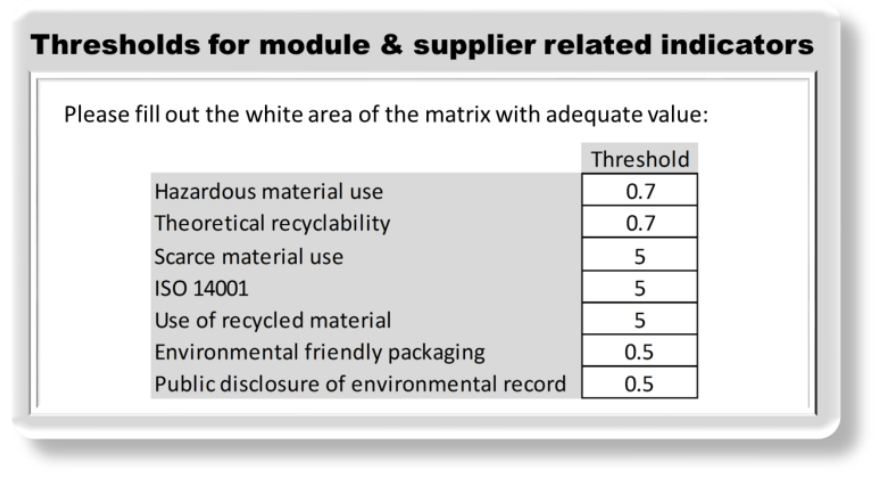

Fig. 20 Thresholds for module \& supplier related indicators

Using the thresholds provided, we can see that (Fig. 21) engines 3 and 5 and batteries 1 and 5 are weeded out; and the suppliers 3, 5, and 7 are eliminated. However, since the supplier 7 provides battery 4 also, the battery 4 should be weeded out because of the unsatisfactory performance of its supplier.

\begin{tabular}{|c|c|c|c|c|c|c|c|c|}
\hline & \multicolumn{3}{|c|}{ Module related environmental indicators } & & \multicolumn{4}{|c|}{ Supplier related environmental indicators } \\
\hline & $\begin{array}{l}\text { Hazardous } \\
\text { material use }\end{array}$ & $\begin{array}{l}\text { Theoretical } \\
\text { recyclability }\end{array}$ & Scarce material use & & ISO 14001 & $\begin{array}{l}\text { Use of recycled } \\
\text { material }\end{array}$ & $\begin{array}{c}\text { Environmental } \\
\text { friendly packaging }\end{array}$ & $\begin{array}{l}\text { Public disclosure of } \\
\text { environmental record }\end{array}$ \\
\hline & (Probability: 0-1) & (Percentage: 0-1) & (Satisfaction: 1-10) & & (Satisfaction: 1 or 10$)$ & (Satisfaction: 1-10) & (Percentage: 0-1) & (Ratio: 0-1) \\
\hline & 0.7 & 0.7 & 5 & & 5 & 5 & 0.5 & 0.5 \\
\hline Module & & & & \multicolumn{5}{|c|}{ Supplier } \\
\hline Engine 1 & 0.9 & 0.9 & 7 & \multirow{3}{*}{$\# 1$} & \multirow{3}{*}{10} & \multirow{3}{*}{8} & \multirow{3}{*}{0.7} & \multirow{3}{*}{0.5} \\
\hline Engine 2 & 0.9 & 0.9 & 7 & & & & & \\
\hline Engine 3 & 0.9 & 0.9 & 4 & & & & & \\
\hline Engine 4 & 0.9 & 0.9 & 7 & $\# 2$ & 10 & I & 0.8 & 0.6 \\
\hline Engine 5 & 0.9 & 0.9 & 7 & $\# 3$ & 10 & 2 & 0.7 & 0.2 \\
\hline Engine 6 & 0.9 & 0.9 & 7 & $\# 4$ & 10 & 6 & 0.7 & 0.7 \\
\hline Battery 1 & 0.8 & 0.8 & 4) & $\# 5$ & 10 & 8 & 0.7 & 0.4 \\
\hline Battery 2 & 0.8 & 0.7 & 6 & \multirow{2}{*}{ \#6 } & \multirow{2}{*}{10} & \multirow{2}{*}{7} & \multirow{2}{*}{0.6} & \multirow{2}{*}{0.6} \\
\hline Battery 3 & 0.8 & 0.7 & 6 & & & & & \\
\hline Battery 4 & 0.8 & 0.7 & 6 & \multirow{2}{*}{$\# 7$} & & \multirow{2}{*}{7} & & \multirow{2}{*}{0.3} \\
\hline Battery 5 & $0.1)$ & 0.6 & 6 & & & & & \\
\hline Battery 6 & 0.8 & 0.7 & 6 & $\# 8$ & 10 & 6 & 0.8 & 0.6 \\
\hline
\end{tabular}

Fig. 21 Filtering using module and supplir related indicators

When estimating environmental performance, battery 5 (Nickel-Cadmium Battery) received a very low score for "Hazardous material use" since one of the core material in this battery is Cadmium, which is toxic. For scarce material use, Engine 3 received a low score because of the utilization of Aluminum. Battery 1 $(\mathrm{NiMH})$ uses approximately $4.5 \mathrm{~kg}$ of rare earth metals, while the Li-based batteries contain only about 1 $\mathrm{kg}$ of rare earths (Ford, 2012). The supplier 5 does not have an effective reverse logistic system, and the supplier 7 does not have ISO 14001 certification. After filtering, new modules that were found appropriate are added into database, and the matrix $\mathrm{M}_{2}$ is updated by experts (Figure 22). 
Ye Y., Jankavic M., Kremer G., Yannou B., Leray Y., Bocquet J.-C., "Integration of Enviranmental Impact Estimation in System Architecture \& Supplier Identification", Research in Engineering Design vol., 2015, dai: 10.1007/s00163-015-0208-x.

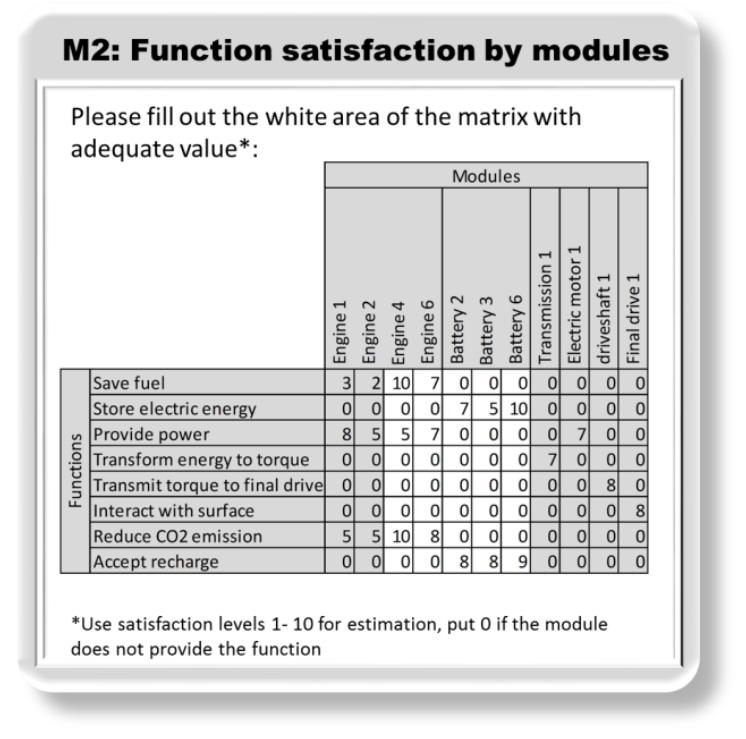

Fig. 22 Function - module relations with new modules

The relations between modules and suppliers are also provided by experts, indicating which module is provided by which supplier.

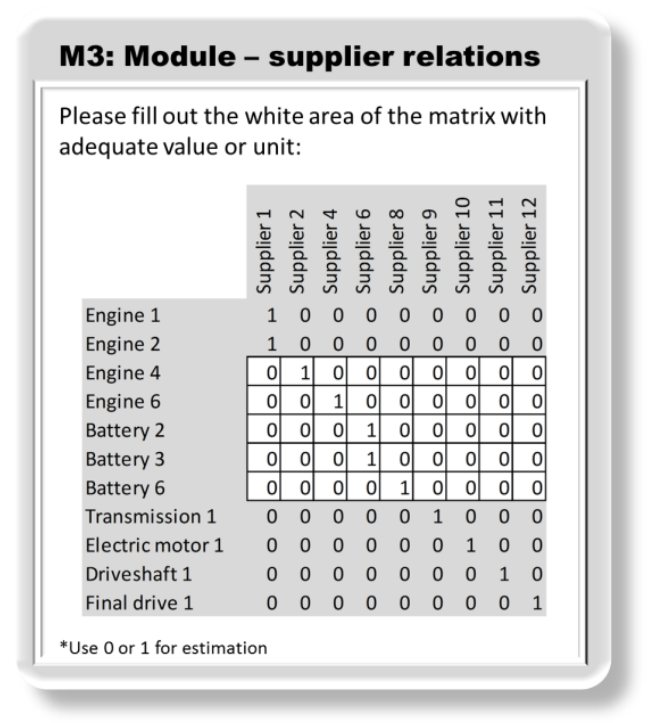

Fig. 23 M3: module - supplier relations

Based on modules shown in $\mathrm{M}_{2}$ all possible architectures are generated (Fig. 24) by taking one module from each module type, since the powertrain of a plug-in hybrid electric vehicle is composed of an engine, a battery, a transmission, an electric motor, a driveshaft and a final drive. 
Ye Y., Jankovic M., Kremer G., Yannou B., Leray Y., Bocquet J.-C., "Integration of Environmental Impact Estimation in System Architecture \& Supplier Identification", Research in Engineering Design vol., 2015, dai: 10.1007/s00163-015-0208-x.

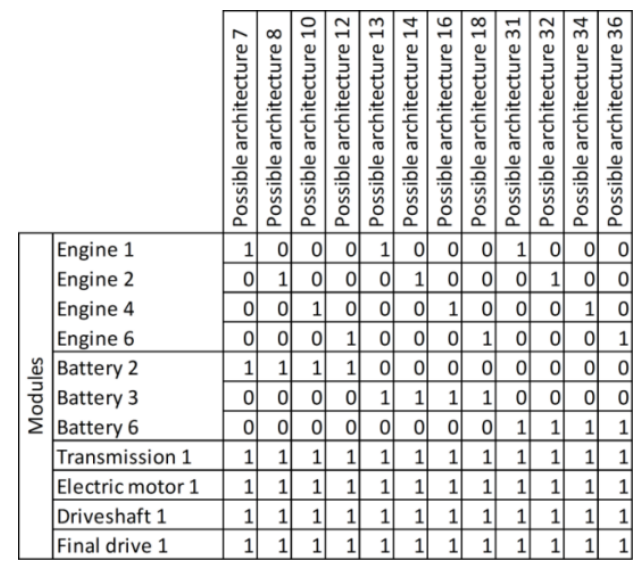

Fig. 24 Generated possible architectures

\subsection{Phase III - Evaluating uncertainty \& requirements satisfaction}

The objective of this phase is to calculate uncertainty and requirements satisfaction for all possible architectures. Three types of uncertainties are considered when calculating the overall uncertainty of an architecture: (1) interface compatibilities between modules due to innovation integration, (2) the uncertainty of modules (representing the probability that the module can be developed successfully by suppliers), and (3) the probability that a supplier and the OEM can work well together. ASIT-E is based on expert estimation for these three types of uncertainty, shown in Fig. 25, Fig. 26, and Fig. 27.

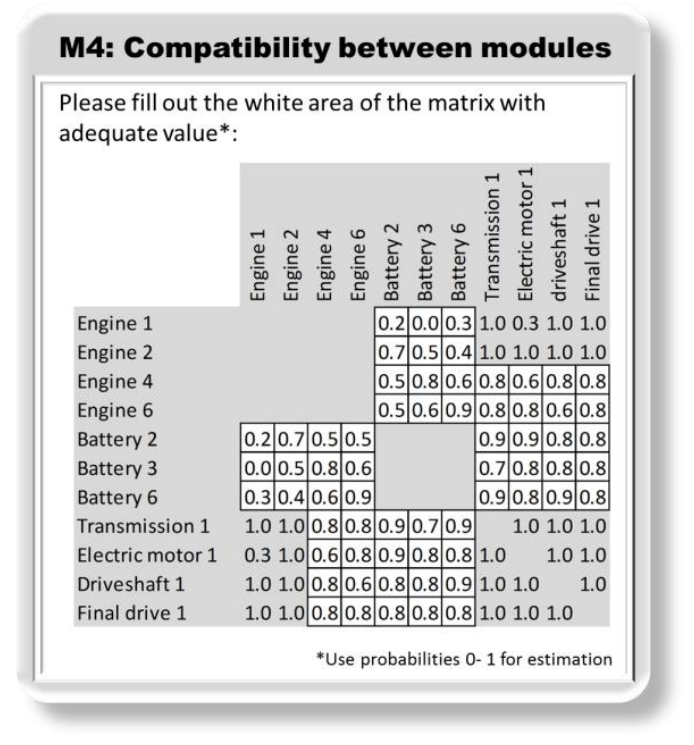

Fig. 25 Expert estimation of compatibility between modules 


\section{Ye Y., Jankavic M., Kremer G., Yannou B., Leray Y., Bacquet J.-C.., "Integration of Environmental Impact Estimation in System Architecture \& Supplier Identification", Research in Engineering Design vol., 2015, dai: 10.1007/s00163-015-0208-x.}

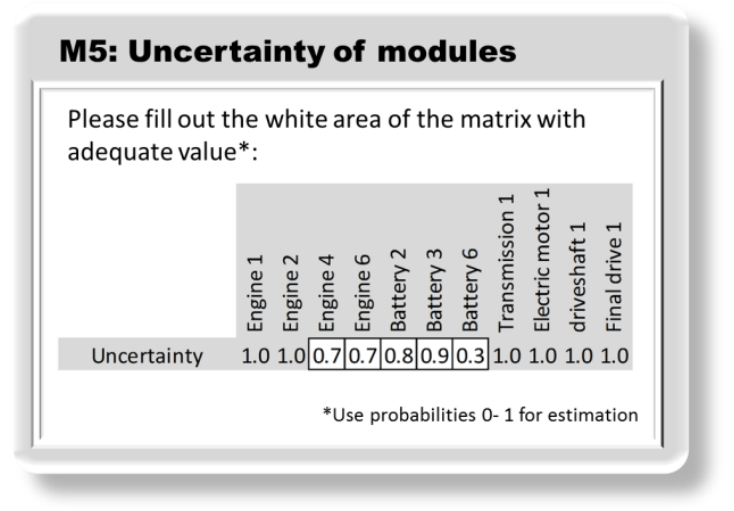

Fig. 26 Expert estimation of module uncertainty

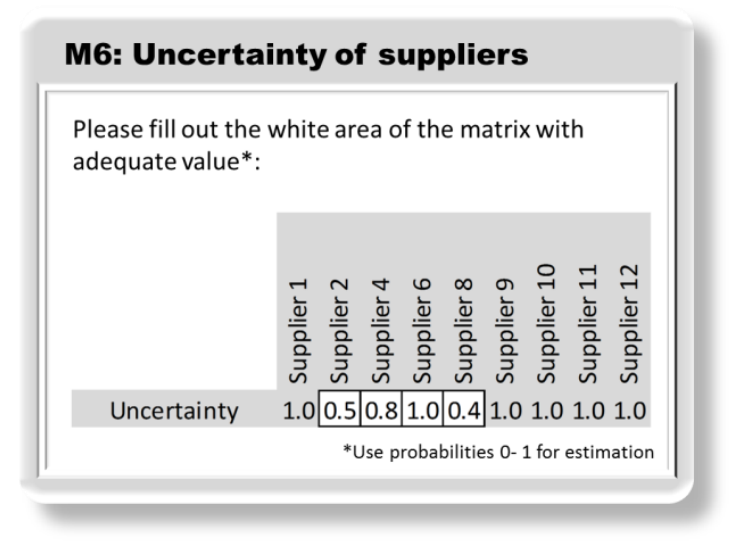

Fig. 27 Expert estimation of supplier uncertainty

Since module uncertainty (the probability that the module can be developed successfully), supplier uncertainty (the probability that the OEM and the supplier can work well together) and compatibility between modules can all be considered in probabilistic terms, we define the uncertainty of an architecture as the product of all its modules' uncertainties, its suppliers' uncertainties and the compatibilities between the modules. This definition anchors on the independence of probabilities.

Done in a similar way as in calculating the requirements satisfaction by existing products, the requirements satisfaction by possible architectures is calculated using the matrix $\mathbf{M}_{2}$ (in Fig. 22) and the matrix $\mathbf{M}_{1}$ (in Fig. 11). In this case, we assume equal importance of the requirements (this assumption can be changed if needed). An overall requirements satisfaction score is obtained for each of the possible architectures by calculating the average of all requirements satisfaction scores for the architecture.

The obtained uncertainties and satisfaction levels are presented in Fig. 28. The "overall uncertainty" represents the overall confidence level of an architecture. In order to estimate the confidence of one architecture we used overall confidence levels that accounts for all uncertainties in one architecture. For example if this indicator is $80 \%$, this means that we almost have certain maturity and confidence in an architecture. The requirement satisfaction represents the ability of an architecture to meet the requirements. Bigger the number is, better the architecture satisfies the requirements.

\begin{tabular}{lllllllllllll} 
Architecture & 7 & 8 & 10 & 12 & 13 & 14 & 16 & 18 & 31 & 32 & 34 & 36 \\
\hline Overall uncertainty & 0.02 & 0.29 & 0.02 & 0.04 & 0.00 & 0.16 & 0.02 & 0.03 & 0.01 & 0.02 & 0.00 & 0.01 \\
Requirement satisfaction & 6.3 & 6.0 & 8.2 & 7.4 & 6.0 & 5.7 & 7.8 & 7.1 & 7.0 & 6.7 & 8.8 & 8.1
\end{tabular}

Fig. 28 Uncertainty and requirements satisfaction for possible architectures 


\section{Ye Y., Jankavic M., Kremer G., Yannau B., Leray Y., Bacquet J.-¿., "Integration of Enviranmental Impact Estimation in System Architecture \& Supplier Identification", Research in Engineering Design vol., 2015, dai: 10.1007/s00163-015-0208-x.}

\subsection{Phase IV - Uncertainty \& requirements satisfaction filtering}

The aim of this phase is to control the overall uncertainty and requirement satisfaction of architectures and at the same time reduce the number of candidates (architectures and suppliers) by using uncertainty and requirement satisfaction thresholds. Considering the effort required for further analyzing the candidates as well as keeping the choices as open as possible, an "adequate number" of candidates can be defined by experts conjointly with stakeholders, which greatly depends on the project undertaken. It is obvious that higher the value of the thresholds, better are the candidate architectures according to the definition of "overall uncertainty" and "requirement satisfaction". At the same time, the minimum expectation of uncertainty level and requirement satisfaction level need to be decided by experts and stakeholders jointly. Therefore, the definition of the thresholds is a balance between candidate number and uncertainty \& requirement satisfaction levels.

For the case at hand, experts set the candidate number at 5 , while the uncertainty threshold is 0.02 , and the satisfaction threshold is 6.5. Therefore, all architectures with uncertainty lower than 0.02 and satisfaction level lower than 6.5 are eliminated. After filtering, architectures 10, 12, 16, 18, 32 remain, as shown in Fig. 29 , for final consideration. By using matrix mapping, it can be seen that engine 1 is filtered out."

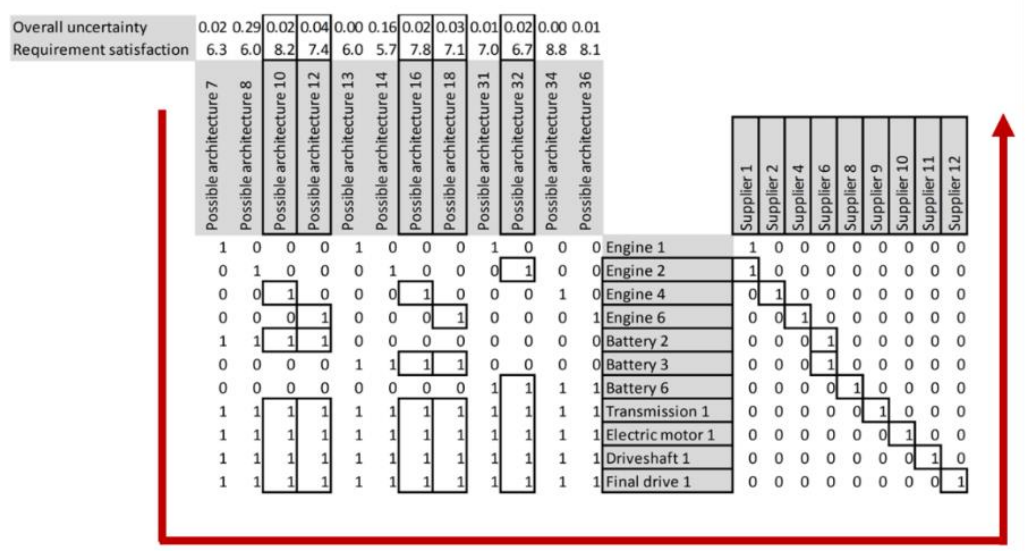

Fig. 29 Uncertainty and satisfaction filtering of possible architectures

\subsection{Phase V-Estimating architecture related indicators \& filtering}

The objective of this phase is to filter remaining architectures using their performances in electricity consumption, water consumption and $\mathrm{CO}_{2}$ emission. The reason that this step is not done in parallel with uncertainty and requirements satisfaction filtering is that the estimation of these three environmental indicators require relatively more information and processing. Therefore, it is necessary to reduce the number of architectures first by uncertainty and requirements satisfaction thresholds.

The electricity consumption, water consumption and $\mathrm{CO}_{2}$ emission during the entire life time of an architecture depend on numerous factors, and are difficult to estimate. Therefore at the conceptual stage of engineering design, we can only expect to have a rough idea about these three factors in order to compare options. Although "the entire life time of an architecture" is considered, it is neither efficient nor possible to consider all lifecycle phases for each indicator. Therefore, we consider only the most important phases for each indicator. Another important factor to consider during estimation is the lifespan of each module. As suggested by WEEE, we assume that modules in an EOL system are collected and then re-used if they did not attain their lifespan. Therefore, if other characteristics of two modules are the same, but one has a longer lifespan, we should consider that the module with a longer lifespan is more environmentally friendly. The value of the three indicators (electricity consumption, water consumption and $\mathrm{CO}_{2}$ emission) for each architecture is calculated based on estimations provided by experts, with the consideration of the most important lifecycle phases, and the lifespan of each module. Finally, thresholds are used to filter architectures and identify candidates. 


\section{Ye Y., Jankavic M., Kremer G., Yannou B., Leray Y., Bacquet J.-C.., "Integration of Environmental Impact Estimation in System Architecture \& Supplier Identification", Research in Engineering Design vol., 2015, dai: 10.1007/s00163-015-0208-x.}

\subsubsection{Lifecycle phase selection, lifespan, and unit}

Before estimation, ASIT-E asks experts to select the most important lifecycle phases for each indicator according to the type of system being designed (shown in Fig. 30). Normally, a phase is neglected if one of the following criteria is satisfied:

1) The consumption or emission is negligible in comparison to other phases;

2) The consumption or emission of the phase is similar for all possible architectures, therefore does not affect the comparison between architectures.

\section{Important lifecycle phases for indicators}

Please select the most important lifecycle phases for each indicator:

\begin{tabular}{|c|c|c|c|c|c|c|c|}
\hline & \multirow[b]{2}{*}{$\begin{array}{l}\text { Product type: } \\
\text { automoblie powertrain }\end{array}$} & \multicolumn{6}{|c|}{ Product Lifecycle Phases } \\
\hline & & $\begin{array}{l}\text { Module } \\
\text { production }\end{array}$ & $\begin{array}{l}\text { Supplier-OEM } \\
\text { transportation }\end{array}$ & Assembly & $\begin{array}{l}\text { OEM - storage } \\
\text { transportation }\end{array}$ & Storage & Utilization \\
\hline \multirow{7}{*}{ 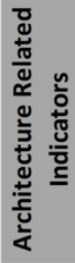 } & \multirow{4}{*}{$\begin{array}{l}\text { Electricity consumption } \\
\text { Water consumption } \\
\mathrm{CO} 2 \text { emission }\end{array}$} & $v$ & & & & & $\checkmark$ \\
\hline & & $\checkmark$ & & & & & \\
\hline & & $\checkmark$ & $\checkmark$ & & & & $\checkmark$ \\
\hline & & Collection & $\begin{array}{l}\text { Inspection \& } \\
\text { classification }\end{array}$ & $\begin{array}{c}\text { Re-use } \\
\text { (module) }\end{array}$ & $\begin{array}{c}\text { Recycle } \\
\text { (material) }\end{array}$ & Other recovery & Disposal \\
\hline & \multirow{3}{*}{$\begin{array}{l}\text { Electricity consumption } \\
\text { Water consumption } \\
\text { CO2 emission }\end{array}$} & & & & & & \\
\hline & & & & & $v$ & & $v$ \\
\hline & & & & & & & \\
\hline
\end{tabular}

Fig. 30 Lifecycle phases selection for indicators

ASIT-E also asks for the estimation of a lifespan for each module and for the entire architecture (shown in Fig. 31). The units that will be used for estimation are also defined in order to facilitate further integration.

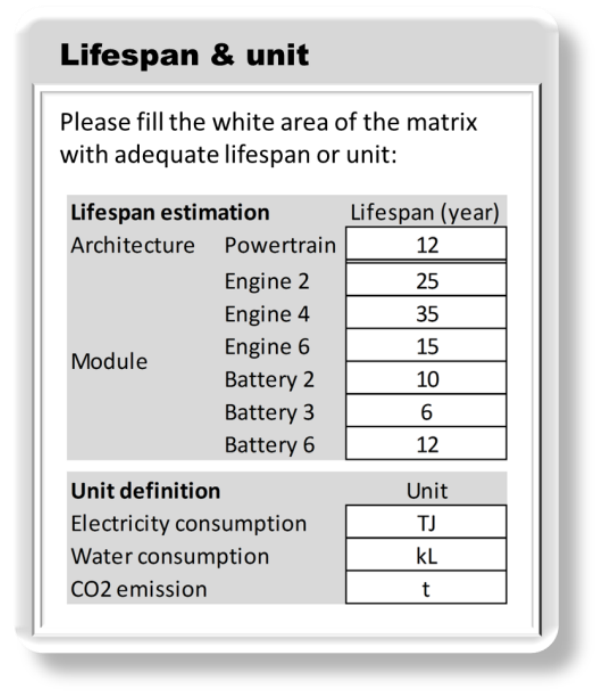

Fig. 31 Lifespan estimation \& unit definition

In ASIT-E, we assume that the lifespan of the entire system under design (the powertrain in this case) is defined. This lifespan can be defined according to OEMs requirements on the system lifespan or according to market average. In this case study, we assume that the OEM wants the powertrain to last for about 12 years (service unit). Using the lifespan of modules and system, the module depletion can be calculated, 
Ye Y., Jankavic M., Kгеmer G., Yannau B., Leray Y., Bacquet J.-C., "Integration of Enviranmental Impact Estimation in System Architecture \& Supplier Identification", Research in Engineering Design vol., 2015, dai: 10.1007/s00163-015-0208-x.

which represents the used up percentage of a module (e.g., engine) when serving a system (e.g., powertrain) (Fig. 32).

\begin{tabular}{l|cc} 
Module & Module Lifespan (year) & Module depletion per System \\
\hline Engine 2 & 25 & $12 / 25 \sim 1 / 2$ \\
Engine 4 & 35 & $12 / 35 \sim 1 / 3$ \\
Engine 6 & 15 & $12 / 15 \sim 1$ \\
Battery 2 & 10 & $12 / 10 \sim 1$ \\
Battery 3 & 6 & $12 / 6=2$ \\
Battery 6 & 12 & $12 / 12=1$ \\
& & *System lifespan = 12 years
\end{tabular}

Fig. 32 Module depletion per system

The module depletion is an approximation of quotient of system lifespan and module lifespan. When the module depletion is bigger than or equal to 1, it is approximated to the nearest integer; when it is between 0 and 1, it is approximated to a fraction whose denominator is an integer between 1 and 10.In order to facilitate the value integration of different lifecycle phases, the estimation of the three indicators are provided using approximated quantitative values. The units of estimation are provided by experts based on data from previous projects.

\subsubsection{Estimation of architecture related environmental indicators}

The electricity consumption, water consumption, and $\mathrm{CO}_{2}$ emission are estimated by experts using predefined units. For the phase "utilization", the environmental impact is considered for the entire lifespan of the system (12 years in this case).

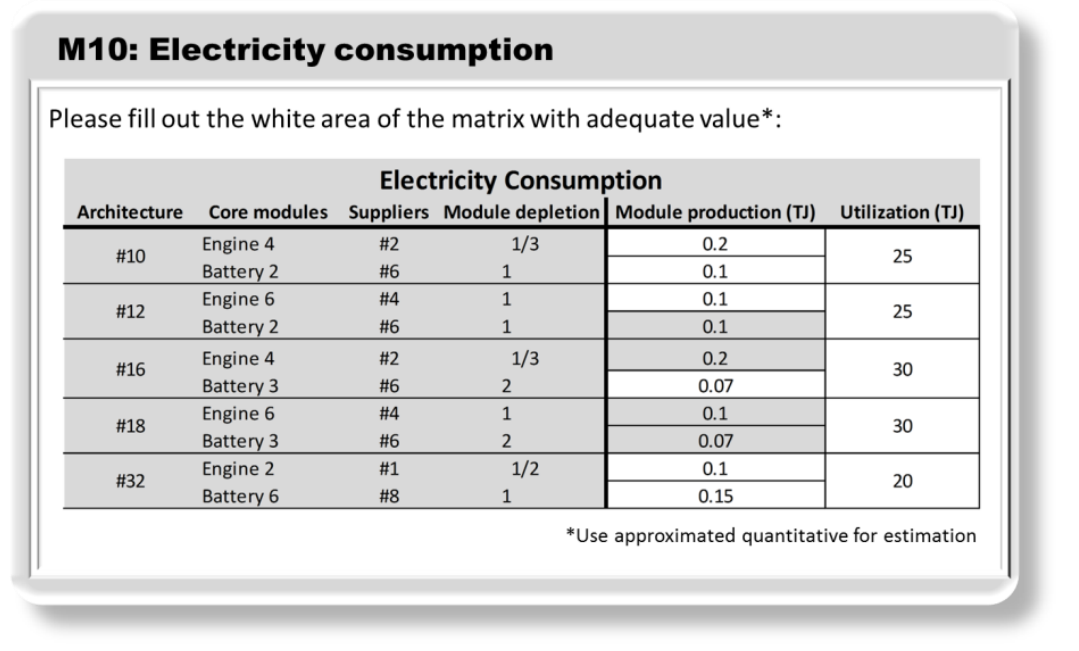

Fig. 33 Experts' estimation of electricity consumption 
Ye Y., Jankovic M., Kremer G., Yannau B., Leray Y., Bocquet J.-C., "Integration of Environmental Impact Estimation in System Architecture \& Supplier Identification", Research in Engineering Design vol., 2015, dai: 10.1007/s00163-015-0208-x.

\section{M11: Water consumption}

Please fill out the white area of the matrix with adequate value*:

\begin{tabular}{|c|c|c|c|c|c|c|}
\hline \multicolumn{7}{|c|}{ Water consumption } \\
\hline Architecture & Core modules & Suppliers & Module depletion & $\begin{array}{c}\text { Module } \\
\text { production (kL) }\end{array}$ & $\begin{array}{c}\text { Recycle } \\
\text { (kL) }\end{array}$ & $\begin{array}{c}\begin{array}{c}\text { Disposal } \\
(\mathbf{k L})\end{array} \\
\end{array}$ \\
\hline \multirow{2}{*}{$\# 10$} & Engine 4 & \#2 & $1 / 3$ & 0.4 & 0.1 & 0.2 \\
\hline & Battery 2 & $\# 6$ & 1 & 0.2 & 0.1 & 0.1 \\
\hline \multirow{2}{*}{$\# 12$} & Engine 6 & $\# 4$ & 1 & 0.3 & 0.1 & 0.2 \\
\hline & Battery 2 & $\# 6$ & 1 & 0.2 & 0.1 & 0.1 \\
\hline \multirow{2}{*}{$\# 16$} & Engine 4 & \#2 & $1 / 3$ & 0.4 & 0.1 & 0.2 \\
\hline & Battery 3 & $\# 6$ & 2 & 0.2 & 0.3 & 0.2 \\
\hline \multirow{2}{*}{$\# 18$} & Engine 6 & \#4 & 1 & 0.3 & 0.1 & 0.2 \\
\hline & Battery 3 & \#6 & 2 & 0.2 & 0.3 & 0.2 \\
\hline \multirow{2}{*}{$\# 32$} & Engine 2 & $\# 1$ & $1 / 2$ & 0.3 & 0.1 & 0.2 \\
\hline & Battery 6 & $\# 8$ & 1 & 0.3 & 0.1 & 0.3 \\
\hline
\end{tabular}

*Use approximated quantitative for estimation

Fig. 34 Experts' estimation of water consumption

\section{M12: C02 emission}

Please fill out the white area of the matrix with adequate value*:

\begin{tabular}{|c|c|c|c|c|c|c|c|c|c|c|}
\hline \multirow{3}{*}{ Architecture } & \multirow{3}{*}{$\begin{array}{c}\text { Core } \\
\text { modules }\end{array}$} & \multirow{3}{*}{ Suppliers } & \multicolumn{7}{|c|}{$\mathrm{CO}_{2}$ Emission } & \multirow{3}{*}{$\begin{array}{c}\text { Utilization } \\
\left(\mathrm{tCO}_{2}\right)\end{array}$} \\
\hline & & & \multirow{2}{*}{$\begin{array}{c}\text { Module } \\
\text { depletion }\end{array}$} & \multirow{2}{*}{$\begin{array}{c}\text { Module } \\
\text { weight }(\mathrm{kg})\end{array}$} & \multirow{2}{*}{$\mid \begin{array}{c}\text { Module } \\
\text { production } \\
\left(\mathrm{tCO}_{2}\right)\end{array}$} & \multicolumn{4}{|c|}{ Supplier-OEM transportation } & \\
\hline & & & & & & \begin{tabular}{|c|} 
Air \\
$(\mathrm{km})$
\end{tabular} & \begin{tabular}{|l} 
Rail \\
$(\mathrm{km})$
\end{tabular} & $\begin{array}{l}\text { Road } \\
(\mathrm{km})\end{array}$ & $\begin{array}{c}\text { Maritime } \\
(\mathrm{km})\end{array}$ & \\
\hline \multirow{2}{*}{$\# 10$} & Engine 4 & $\# 2$ & $1 / 3$ & 70 & 0.3 & 0 & 3000 & & & \multirow{2}{*}{0} \\
\hline & Battery 2 & $\# 6$ & 1 & 200 & 0.5 & 0 & & 500 & & \\
\hline \multirow{2}{*}{$\# 12$} & Engine 6 & $\# 4$ & 1 & 150 & 0.25 & 0 & & 500 & & \multirow{2}{*}{10} \\
\hline & Battery 2 & $\# 6$ & 1 & 200 & 0.5 & 0 & & 500 & & \\
\hline \multirow{2}{*}{$\# 16$} & Engine 4 & \#2 & $1 / 3$ & 70 & 0.3 & 0 & 3000 & & & \multirow{2}{*}{0} \\
\hline & Battery 3 & $\# 6$ & 2 & 150 & 0.5 & 0 & & 500 & & \\
\hline \multirow{2}{*}{$\# 18$} & Engine 6 & $\# 4$ & 1 & 150 & 0.25 & 0 & & 500 & & \multirow{2}{*}{10} \\
\hline & Battery 3 & $\# 6$ & 2 & 150 & 0.5 & 0 & & 500 & & \\
\hline \multirow{2}{*}{$\# 32$} & Engine 2 & $\# 1$ & $1 / 2$ & 100 & 0.25 & 0 & 8000 & & & \multirow[b]{2}{*}{8} \\
\hline & Battery 6 & \#8 & 1 & 100 & 0.6 & 0 & & 200 & 8000 & \\
\hline
\end{tabular}

*Use approximated quantitative for estimation

Fig. 35 Experts' estimation of $\mathrm{CO}_{2}$ emission

The area with a grey background is filled in automatically by ASIT-E. For example, the $\mathrm{CO}_{2}$ emitted during "module production" for Engine 4 is always the same $(0.3 \mathrm{t})$, it does not matter if it is Architecture 10 or Architecture 18. Therefore, when experts estimated the $\mathrm{CO}_{2}$ emission for manufacturing engine 4 in architecture 10, the $\mathrm{CO}_{2}$ emission for producing engine 4 in architecture 16 can be filled by ASIT-E using the same value.

Different from other phases, the $\mathrm{CO}_{2}$ emission of transportation is not estimated directly by experts due to its complexity. Instead, ASIT-E asks experts to provide estimation of module weight and transportation distance by different transportation means. For calculation of $\mathrm{CO}_{2}$ emission, we use equation:

$\mathrm{CO}_{2}$ emission $=$ emission factor $($ depends on transportation mode $) \times$ mass $\times$ distance

The emission factors is an average that depends on transportation mode, and is adopted from ADEME (2010) as shown in Fig. 36. 
Ye Y., Jankavic M., Kremer G., Yannou B., Leray Y., Bacquet J.-C.., "Integration of Enviranmental Impact Estimation in System Architecture \& Supplier Identification", Research in Engineering Design vol., 2015, dai: 10.1007/s00163-015-0208-x.

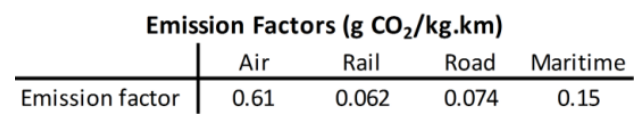

Fig. 36 Emission factors (adopted from ADEME (2010))

After calculation, the $\mathrm{CO}_{2}$ emission estimates of architectures for different lifecycle phases are shown in Fig. 37.

\begin{tabular}{|c|c|c|c|c|c|c|}
\hline Architecture & $\begin{array}{c}\text { Core } \\
\text { modules }\end{array}$ & Suppliers & $\begin{array}{c}\text { Module } \\
\text { depletion }\end{array}$ & $\begin{array}{c}\text { Module } \\
\text { production } \\
\left(\mathrm{t} \mathrm{CO}_{2}\right)\end{array}$ & $\begin{array}{c}\text { Supplier-OEM } \\
\text { transportation } \\
\text { (t CO2) }\end{array}$ & $\begin{array}{l}\text { Utilization } \\
\left(\mathrm{t} \mathrm{CO}_{2}\right)\end{array}$ \\
\hline \multirow{2}{*}{$\# 10$} & Engine 4 & $\# 2$ & $1 / 3$ & 0.3 & 0.0013 & \multirow{2}{*}{0} \\
\hline & Battery 2 & \#6 & 1 & 0.5 & 0.0074 & \\
\hline \multirow{2}{*}{$\# 12$} & Engine 6 & $\# 4$ & 1 & 0.25 & 0.0056 & \multirow{2}{*}{10} \\
\hline & Battery 2 & $\# 6$ & 1 & 0.5 & 0.0074 & \\
\hline \multirow{2}{*}{ \#16 } & Engine 4 & $\# 2$ & $1 / 3$ & 0.3 & 0.0013 & \multirow{2}{*}{0} \\
\hline & Battery 3 & $\# 6$ & 2 & 0.5 & 0.0056 & \\
\hline \multirow{2}{*}{$\# 18$} & Engine 6 & $\# 4$ & 1 & 0.25 & 0.0056 & \multirow{2}{*}{10} \\
\hline & Battery 3 & \#6 & 2 & 0.5 & 0.0056 & \\
\hline \multirow{2}{*}{$\# 32$} & Engine 2 & $\# 1$ & $1 / 2$ & 0.25 & 0.0050 & \multirow{2}{*}{8} \\
\hline & Battery 6 & $\# 8$ & 1 & 0.6 & 0.1215 & \\
\hline
\end{tabular}

Fig. 37 Calculation of $\mathrm{CO} 2$ emission for transportation

\subsubsection{Calculation of environmental indicators \& architecture filtering}

Estimations of each indicator for each module/architecture are integrated to calculate the environmental performance of each possible powertrain regarding $\mathrm{CO}_{2}$ emission, water consumption, and electricity consumption. The powertrains are then filtered to get the final architecture and supplier candidates. We have seen that the powertrain is composed of six modules. Since in this case study, the transmission, electric motor, driveshaft, and final drive are the same for all architectural options, we consider only the two core modules (which are different from concept to concept) — engine and battery for comparison.

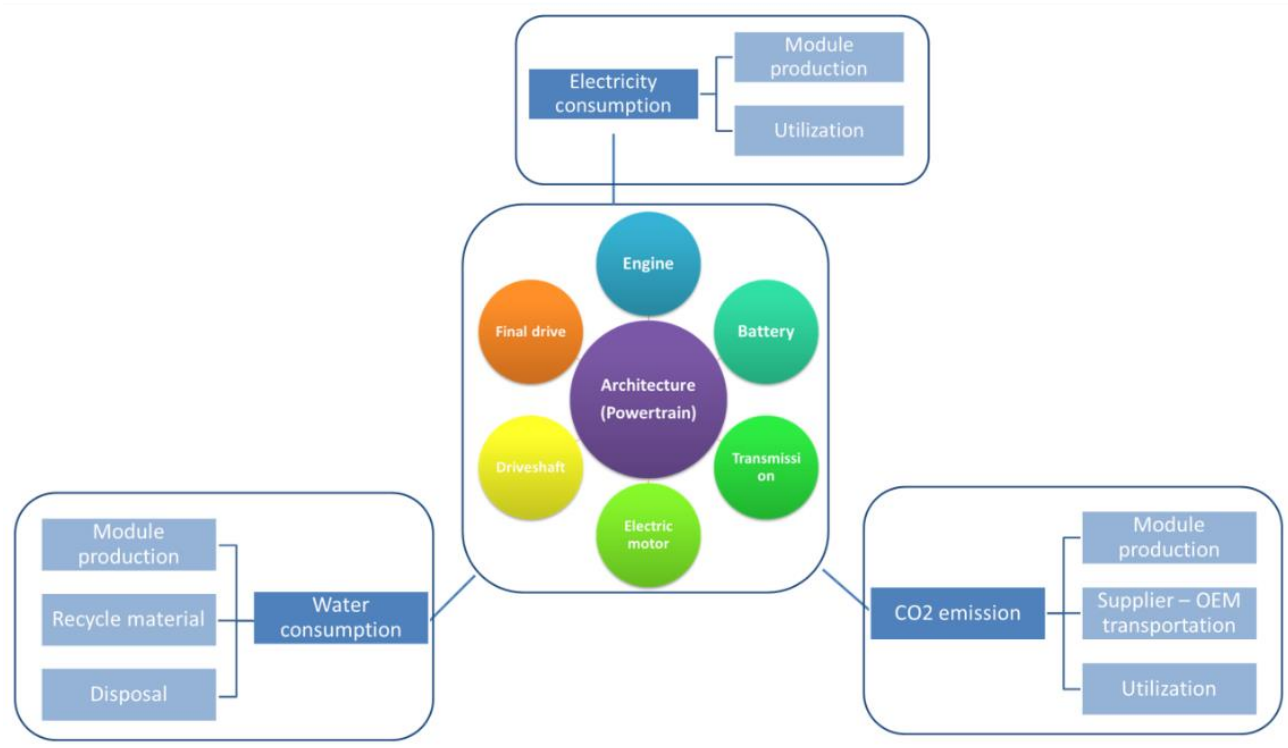

Fig. 38 Integration of architecture related indicators 


\section{Ye Y., Jankavic M., Kremer G., Yannau B., Leray Y., Bocquet J.-С., "Integration of Enviranmental Impact Estimation in System Architecture \& Supplier Identification", Research in Engineering Design vol., 2015, dai: 10.1007/s00163-015-0208-x.}

As a first step of integration, we calculate the electricity consumption, water consumption, and $\mathrm{CO}_{2}$ emission for each powertrain concept separately, before integrating these three indicators for each concept during the second step. These three indicators are estimated for different lifecycle phases for the powertrain in the previous section. Therefore, it is sufficient to add consumption/emission of each phase up to get the overall value for the entire lifecycle, as estimates are quantitative. However, the lifespan of a module plays an important role in the calculation. For example, if two batteries are needed during the entire lifecycle of powertrain, the pollution of producing the battery should be counted twice. Therefore, when adding the pollution of each lifecycle phase, factor that is related to the lifespan of each module should be considered for module related phases: "module depletion factor", or " $f_{n}$ "(Fig. 39). The module depletion factor depends also on the type of architecture being considered.

\begin{tabular}{|c|c|c|c|c|}
\hline & Module Dep & on $\mathbf{F}$ & $(f n)$ & \\
\hline & & & deple & \\
\hline & & $n>1$ & $n=1$ & $n<1$ \\
\hline & Module production & $\mathrm{n}$ & 1 & $n$ \\
\hline & Supplier-OEM transportation & $\mathrm{n}$ & 1 & $\mathrm{n}$ \\
\hline & Assembly & 1 & 1 & 1 \\
\hline & OEM - storage transportation & 1 & 1 & 1 \\
\hline 究 & Storage & 1 & 1 & 1 \\
\hline ¿ & Utilization & 1 & 1 & 1 \\
\hline$\frac{\pi}{y}$ & Collection & 1 & 1 & 1 \\
\hline $\bar{s}$ & Inspection \& classification & 1 & 1 & 1 \\
\hline & Re-use (module) & 0 & 0 & $1-n$ \\
\hline & Recycle (material) & $\mathrm{n}$ & 1 & $\mathrm{n}$ \\
\hline & Other recovery & $\mathrm{n}$ & 1 & $\mathrm{n}$ \\
\hline & Disposal & $\mathrm{n}$ & 1 & $\mathrm{n}$ \\
\hline
\end{tabular}

Fig. 39 Module depletion factor

Assume $n=1 / 3$ (for engine \#4 for example), which means that the engine \#4 can serve 3 powertrains in its lifespan. Therefore, the module production and supplier-OEM transportation should be counted 1/3 times in each powertrain lifecycle. From the lifecycle "assembly" to "inspection \& classification", the estimations are based on the entire powertrain (e.g., the assembly is the assembly of the entire powertrain, not assembly of the module). Therefore, the lifespan of each module does not influence these lifecycle phases. If a module can be used in 3 powertrains, it can be re-used twice and recycled/recovered/disposed once. Therefore, for each powertrain lifecycle (12 years), the pollution of reuse should be counted $2 / 3$ times, and recycled/recovered/disposed should be counted 1/3 times. For the calculation of indicators, we use electricity consumption of architecture \#10 as an example. Architecture \#10 is composed of core modules engine \#4 and battery \#2. The important lifecycle phases are module production and utilization; therefore, it is sufficient to calculate electricity consumption of each important phase and then sum them up.

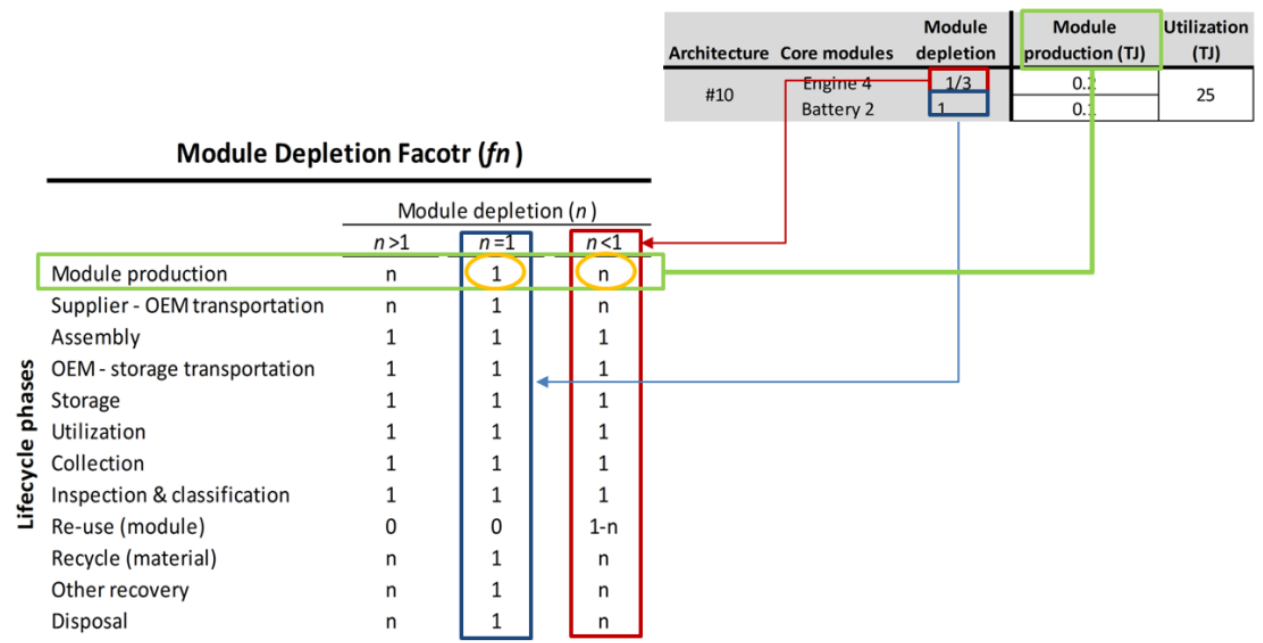




\section{Ye Y., Jankavic M., Kremer G., Yannou B., Leray Y., Bacquet J.-C., "Integration of Environmental Impact Estimation in System Architecture \& Supplier Identification", Research in Engineering Design vol., 2015, dai: 10.1007/s00163-015-0208-x.}

\section{Fig. 40 Integration}

For the phase of module production, the module depletion factor needs to be considered for the two modules: Engine 4: Module depletion $=\mathrm{n}=1 / 3$

$\rightarrow$ Module depletion factor for module production $f n(\mathrm{E} 4)=\mathrm{n}=1 / 3$

Battery 2: Module depletion $=1$

$\rightarrow$ Module depletion factor for module production $f n(\mathrm{~B} 2)=1$

Therefore, the electricity consumption for the module production of architecture 10 is: $f n(E 4) \times$ Electricity consumption of producing $\mathrm{E} 4+f n(B 2) \times$ Electricity consumption of producing B2

$=\frac{1}{3} \times 0.2+1 \times 0.1=0.17(T J)$

The electricity consumption when using architecture 10 (for 12 years) is 25 TJ. The electricity consumption of the entire cycle of architecture \#10 is:

Electricity consumption of production + Electricity consumption of utilization $=0.17+25=25.17(T J)$

The water consumption and $\mathrm{CO}_{2}$ emission follow the same principle as electricity consumption. The environmental impact estimates for the three architecture related indicators are shown in Fig. 41.

\begin{tabular}{cc|ccc} 
Architecture & Supplier & $\begin{array}{c}\text { Electricity } \\
\text { consumption } \\
\text { (TJ) }\end{array}$ & $\begin{array}{c}\text { Water } \\
\text { consumption } \\
\text { (kL) }\end{array}$ & $\begin{array}{c}\text { CO2 emission } \\
\text { (t) }\end{array}$ \\
\hline$\# 10$ & $\# 2, \# 6$ & 25.17 & 0.67 & 0.61 \\
$\# 12$ & $\# 4, \# 6$ & 25.20 & 1.00 & 10.76 \\
$\# 16$ & $\# 2, \# 6$ & 30.21 & 1.07 & 1.11 \\
$\# 18$ & $\# 4, \# 6$ & 30.24 & 1.40 & 11.27 \\
$\# 32$ & $\# 1, \# 8$ & 20.20 & 1.00 & 8.85
\end{tabular}

Fig. 41 Environmental impact calculation

For comparison purposes the values of the three indicators are normalized within each indicator category, by dividing the biggest value within the category, as shown in Fig. 42.

\begin{tabular}{cc|ccc} 
Architecture & Supplier & $\begin{array}{c}\text { Electricity } \\
\text { consumption } \\
\text { (TJ) }\end{array}$ & $\begin{array}{c}\text { Water } \\
\text { consumption } \\
\text { (kL) }\end{array}$ & $\begin{array}{c}\text { CO2 emission } \\
\text { (t) }\end{array}$ \\
\hline$\# 10$ & $\# 2, \# 6$ & 0.83 & 0.48 & 0.05 \\
$\# 12$ & $\# 4, \# 6$ & 0.83 & 0.71 & 0.96 \\
$\# 16$ & $\# 2, \# 6$ & 1.00 & 0.76 & 0.10 \\
$\# 18$ & $\# 4, \# 6$ & 1.00 & 1.00 & 1.00 \\
$\# 32$ & $\# 1, \# 8$ & 0.67 & 0.71 & 0.79
\end{tabular}

Fig. 42 Normalized environmental impact

Assuming equal importance of each indicator (this can be changed if necessary), the overall environmental impact of each architecture is calculated by adding the three indicators for each architecture. The result is normalized by dividing by the biggest value.

\begin{tabular}{cc|cc} 
Architecture Supplier & $\begin{array}{c}\text { Overall } \\
\text { environmental } \\
\text { impact }\end{array}$ & $\begin{array}{c}\text { Normalized } \\
\text { overall impact }\end{array}$ \\
\hline$\# 10$ & $\# 2, \# 6$ & 1.37 & 0.46 \\
$\# 12$ & $\# 4, \# 6$ & 2.50 & 0.83 \\
$\# 16$ & $\# 2, \# 6$ & 1.86 & 0.62 \\
$\# 18$ & $\# 4, \# 6$ & 3.00 & 1.00 \\
$\# 32$ & $\# 1, \# 8$ & 2.17 & 0.72
\end{tabular}

Fig. 43 Normalized overall environmental impact

Finally, experts can set a threshold for the normalized overall impact in order to filter the potential architecture set with a certain level of environmental impact. The purpose of this filtering is to keep a certain 


\section{Ye Y., Jankavic M., Kremer G., Yannau B., Leray Y., Bacquet J.-L., "Integration of Environmental Impact Estimation in System Architecture \& Supplier Identification", Research in Engineering Design vol., 2015, dai: 10.1007/s00163-015-0208-x.}

number of candidates with relatively better environmental performance for further analysis. Therefore, the value of the threshold can be considered as a relative indicator instead of an absolute and can be used for the exploration of the design space. If the threshold is set as 0.8 , Fig. 44 presents the remaining architectures and suppliers after filtering; these are candidates for OEM's further selection.

\begin{tabular}{|c|c|c|c|}
\hline Architecture & Core modules & Module description & Suppliers \\
\hline \multirow{2}{*}{10} & Engine 4 (new) & Steel, hydrogen & 2 (new) \\
\hline & Battery 2 (new) & $\mathrm{LiFePO}_{4}$ & 6 (new) \\
\hline \multirow{2}{*}{16} & Engine 4 (new) & Steel, hydrogen & 2 (new) \\
\hline & Battery 3 (new) & Lithium-ion & $6($ new) \\
\hline \multirow{2}{*}{32} & Engine 2 (existing) & Steel, gasoline & 1 (existing) \\
\hline & Battery 6 (new) & Carbon nanotube electrode lithium & $8($ new) \\
\hline
\end{tabular}

Fig. 44 Identified potential architectures and suppliers

\section{Comparison}

In order to see how considerations for environmental issues influences the architecture and supplier identification results, we compare the result obtained by using ASIT-E to the result obtained using ASIT (where environmental issues are not considered) for the same case study. In ASIT, only requirements satisfaction and uncertainty are considered, but not the environmental issues. Therefore, more concepts are identified using ASIT than using ASIT-E, as expected. The identified engine-battery combinations using ASIT-E and ASIT are shown in Fig. 45. The three concepts identified by ASIT-E are also identified by ASIT, which are represented by bold lines.

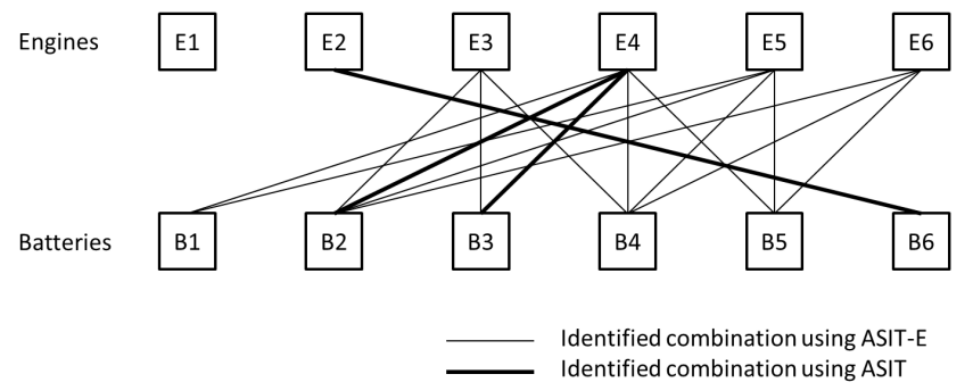

Fig. 45 Result comparison of ASIT-E and ASIT

It can be seen from Fig. 45 that when environmental issues are not considered, engines 3, 5, 6, and batteries $1,4,5$ are all among the identified concepts. However, according to RoHS, the material cadmium contained in battery 5 is a hazardous material, whose utilization is restricted. Battery 1 (NiMH battery) uses approximately $4.5 \mathrm{~kg}$ of rare earth metals, which is much higher than other batteries (which normally use around $1 \mathrm{~kg}$ of rare earth metals). The battery 5 is eliminated because its supplier does not satisfy the environmental requirements (does not have ISO14001 certification, has low capability of using environmental friendly packaging, and has outdated public disclosure of environmental record). As for engines: engine 3 is filtered out by ASIT-E because it uses a high quantity of aluminum, which is among the rare earth materials. Engine 5 is eliminated due to its supplier's incapability of using recycled materials, and the lack of public disclosure of environmental record. Finally, engine 6 is not among ASIT-E's final candidate list because of its unsatisfactory performance regarding $\mathrm{CO}_{2}$ emission, water consumption and electricity consumption during its entire lifecycle.

As discussed at the beginning of the paper, not many methods combine system architecture selection and environmental impact estimation. Therefore, comparative studies are limited. One can only conclude that with integration of environmental factors possible system architecture space is reduced with regard to added criteria. However, the comparison between ASIT-E and ASIT showed that the consideration for environmental issues can effectively weed out many options that fail to meet environmental requirements. By using ASIT-E, OEMs are able to have a general idea about all possible architecture options with regards 


\section{Ye Y., Jankavic M., Kremer G., Yannau B., Leray Y., Bacquet J.-C., "Integration of Enviranmental Impact Estimation in System Architecture \& Supplier Identification", Research in Engineering Design vol., 2015, dai: 10.1007/s00163-015-0208-x.}

to their environmental performances. Moreover, since ASIT-E is built upon ASIT, the architecture's requirements satisfaction capability and uncertainty are also estimated.

By integrating the environmental plug-in into ASIT, we also show the flexible structure ASIT affords to easily add plug-ins. One possible future work would be developing other plug-ins for ASIT to better manage cost, time-to-market, and other factors. The environmental plug-in itself is also very flexible. According to OEMs' different needs, the environmental indicators as well as lifecycle phases can also be customized. However, there are several limitations of ASIT-E that should be acknowledged. Data collection on potential suppliers is challenging. Although required for many countries, the public disclosure of environmental record of suppliers does not guarantee reliable information; however, more and more suppliers have started to provide their eco-profile. In the near future, we believe that such disclosures will become code of practice for suppliers; until then, OEMs can also rely on expert estimation to get approximate environmental information.

Another limitation is related to the method used for calculating the environmental indicators; different OEMs may have different interpretation of the same environmental indicator. Therefore, in this work, it is not practical to provide one indicator calculation method that can be used by all OEMs. For this reason, we focused on illustrating the overall structure of ASIT-E rather than proposing an indicator calculation method. However, we think that developing adequate methods for calculating environmental indicators is a very important issue, and should be investigated in the future.

Finally, an overall usability analysis for ASIT-E should be conducted to ensure its adoption; future research will, in part, be dedicated to this.

\section{Managerial Implications}

Several studies have pointed out the challenges and issues of using theoretical supplier environmental performance measurement models in real world (e.g. Genovese, Koh, Kumar, \& Tripathi (2014); Lake, Acquaye, Genovese, Kumar, \& Koh (2014)).

According to Genovese et al. (2014), six main challenges needed to be considered when proposing supplier environmental performance measurement models to increase their industrial applicability. In this section, we discuss how ASIT-E respond to these challenges:

1. Models should not use one set of environmental indicators for all industries and situations: The flexible structure of ASIT-E enables the customization of environmental indicators according to companies' needs.

2. Models should support collecting data of companies' outsourced partners, in order to achieve an overall environmental performance measurement: By using the lifecycle point of view, ASIT-E enables considering the entire lifecycle of a product thus an overall environmental performance.

3. Models should be able to compare suppliers of different sizes, locations and products supplied; in early stages, it is better if suppliers provide absolute values: For electricity consumption, water consumption and CO2 emission, ASIT-E proposes to use simplified absolute values to enable comparison; a set of techniques is proposed to process collected data and generate a final score for each architecture and supplier.

4. Possibility of finding benchmark for comparison between suppliers: ASIT-E approach is integrating the idea of conducting benchmarks using the data from several suppliers and systems for system architecture identification. The overall aim is to support the design team in this activity.

5. Ensuring consistency in suppliers' responses during data collection: By proposing the framework, ASIT-E specifies the data and information format that the suppliers needed to follow, and thereby aiming at ensuring the consistency in data collection.

6. Providing data validation (for data collected from suppliers): In ASIT-E experts are in charge of validating data collected from suppliers

ASIT-E has been developed to enable industrial implementation of the framework.

\section{Conclusions}

The aim of this work is to support early design phases in investigation of system architecture design phase 


\section{Ye Y., Jankavic M., Kremer G., Yannou B., Leray Y., Bacquet J.-C., "Integration of Environmental Impact Estimation in System Architecture \& Supplier Identification", Research in Engineering Design vol., 2015, dai: 10.1007/s00163-015-0208-x.}

while integrating supplier related data and environmental impact evaluations. In order to do so, a matrixbased method (ASIT-E) was proposed. The contribution of this approach, which considers probabilistic matrices in order to handle several types of uncertainties, is to conjointly consider environmental factors early in design while the data is scarce and fuzzy.

The proposed approach is illustrated using the case of a plug-in hybrid vehicle powertrain design. Through comparison of ASIT-E results to those of a similar method that does not consider environmental issues, we see that ASIT-E affords weeding out of options that have environmental problems. The flexible structure of ASIT-E allows OEMs to customize it by defining their own environmental indicators, lifecycle phases, as well as methods for calculating different indicators. The ASIT-E database also provides a list of necessary data for estimating environmental performance in early design.

\section{References}

ADEME. (2010). Bilan Carbone - Emission factors guide version 6.1. Agence de l'environnement et de la maitrise de l'energie.

Bai, C., \& Sarkis, J. (2010). Integrating sustainability into supplier selection with grey system and rough set methodologies. International Journal of Production Economics, 124(1), 252-264.

Beissmann, T. (2011, September). Toyota Prius Plug-In Hybrid under investigation for Australia, Prius c and MPV locked in for 2012 | CarAdvice. Retrieved April 4, 2014, from http://www.caradvice.com.au/138245/toyota-prius-plug-in-hybrid-under-investigation-foraustralia-prius-c-and-mpv-locked-in-for-2012/

Bhamra, T. A., Evans, S., McAloone, T. C., Simon, M., Poole, S., \& Sweatman, A. (1999). Integrating environmental decisions into the product development process. I. The early stages. In Environmentally Conscious Design and Inverse Manufacturing, 1999. Proceedings. EcoDesign '99: First International Symposium On (pp. 329-333).

Bhutta, M. K. S. (2003). Supplier selection problem: methodology literature review. Journal of International Technology and Information Management, 12(2), 53-72.

Chung, W.-H., Kremer, G. E. O., \& Wysk, R. A. (2014). A Modular Design Approach to Improve Product Life Cycle Performance Based on the Optimization of a Closed-Loop Supply Chain. Journal of Mechanical Design, 136(2), 021001.

Drumwright, M. E. (1994). Socially Responsible Organizational Buying: Environmental Concern as a Noneconomic Buying Criterion. Journal of Marketing, 58(3), 1.

European Commission. (2008). Directive 2008/98/EC on waste (Waste Framework Directive). Ofiicial Journal of the European Union, 312(3).

European Commission. (2014a). Ecodesign - Sustainable and responsible business - Enterprise and Industry. Retrieved April 17, 2014, from http://ec.europa.eu/enterprise/policies/sustainablebusiness/ecodesign/index_en.htm

European Commission. (2014b). Recast of the RoHS Directive - Environment - European Commission. Retrieved April 17, 2014, from http://ec.europa.eu/environment/waste/rohs_eee/

European Commission. (2014c). Waste Electrical and Electronic Equipment - Environment - European Commission. Retrieved April 17, 2014, from http://ec.europa.eu/environment/waste/weee/legis_en.htm

Fiod-Neto, M., \& Back, N. (1994). Assessment of product conception: A critical review. In Proceedings of the 1994 Lancaster International Workshop on Engineering Design.

Ford. (2012). Rare Earth Elements - Sustainability 2012/13 - Ford Motor Company. Retrieved April 20, 2014, from http://corporate.ford.com/microsites/sustainability-report-2012-13/supply-materialselements

Genovese, A., Koh, S. C. L., Kumar, N., \& Tripathi, P. K. (2014). Exploring the challenges in implementing supplier enviromental performance measurement models: a case study. Production Planning \& Control, 25(13-14), 1198-1211.

Georgiadis, P., \& Besiou, M. (2010). Environmental and economical sustainability of WEEE closed-loop supply chains with recycling: a system dynamics analysis. The International Journal of Advanced Manufacturing Technology, 47(5-8), 475-493.

Grisel, L., \& Duranthon, G. (2001). Pratiquer l'éco-conception: lignes directrices. AFNOR.

Hallstedt, S., Ny, H., Robèrt, K.-H., \& Broman, G. (2010). An approach to assessing sustainability integration in strategic decision systems for product development. Journal of Cleaner Production, 18(8), 703-712. 
Ye Y., Jankavic M., Kremer G., Yannou B., Leray Y., Bacquet J.-C.., "Integration of Enviranmental Impact Estimation in System Architecture \& Supplier Identification", Research in Engineering Design vol., 2015, dai: 10.1007/s00163-015-0208-x.

Handfield, R., Walton, S. V., Sroufe, R., \& Melnyk, S. A. (2002). Applying environmental criteria to supplier assessment: A study in the application of the Analytical Hierarchy Process. European Journal of Operational Research, 141(1), 70-87. http://doi.org/10.1016/S0377-2217(01)00261-2

Humphreys, P. ., Wong, Y. ., \& Chan, F. T. . (2003). Integrating environmental criteria into the supplier selection process. Journal of Materials Processing Technology, 138(1-3), 349-356. http://doi.org/10.1016/S0924-0136(03)00097-9

Krikke, H., Bloemhof-Ruwaard, J., \& Van Wassenhove, L. N. (2003). Concurrent product and closedloop supply chain design with an application to refrigerators. International Journal of Production Research, 41(16), 3689-3719.

Lake, A., Acquaye, A., Genovese, A., Kumar, N., \& Koh, S. C. L. (2014). An application of hybrid life cycle assessment as a decision support framework for green supply chain. International Journal of Production Research.

Lamming, R., \& Hampson, J. (1996). The Environment as a Supply Chain Management Issue. British Journal of Management, 7, S45-S62. http://doi.org/10.1111/j.1467-8551.1996.tb00147.x

Lee, H., \& Billington, C. (1992). Managing supply chain inventory: Pitfalls and Opportunities. Sloan Management Review, 33, 65-73.

Lloyd, M. (1994). How green are my suppliers. Purchasing \& Supply Management, 36(Oct).

Michelena, N., \& Papalambros, P. (1995). A Hypergraph Framework to Optimal Model-Based Partitioning of Design Problems (Technical Report No. M-MEAM 95-02). Ann Arbor, Michigan: Department of Mechanical Engineering and Applied Mechanics, University of Michigan.

Nidumolu, R., Prahalad, C. K., \& Rangaswami, M. R. (2009). Why sustainability is now the key driver of innovation. Harvard Business Review, 87(9), 55-64.

Özkır, V., \& Başlıgıl, H. (2012). Modelling product-recovery processes in closed-loop supply-chain network design. International Journal of Production Research, 50(8), 2218-2233.

Porter, M. E., \& Linde, C. V. D. (1995). Green and Competitive: Ending the Stalemate. Harvard Business Review, (September - October). Retrieved from http://hbr.org/product/green-and-competitiveending-the-stalemate/an/95507-PDF-ENG

Pujari, D., Wright, G., \& Peattie, K. (2003). Green and competitive: Influences on environmental new product development performance. Journal of Business Research, 56(8), 657-671. http://doi.org/10.1016/S0148-2963(01)00310-1

Sharma, S. (2000). Managerial Interpretations and Organizational Context as Predictors of Corporate Choice of Environmental Strategy. The Academy of Management Journal, 43(4), 681-697. http://doi.org/10.2307/1556361

Taghaboni-Dutta, F., Trappey, A. J. C., \& Trappey, C. V. (2010). An XML based supply chain integration hub for green product lifecycle management. Expert Systems with Applications, 37(11), 7319-7328.

The ad-hoc Working Group. (2010). Critical raw materials for the EU.

Ye, Y., Jankovic, M., Kremer, G., \& Bocquet, J.-C. (2014). Managing uncertainty in potential supplier identification. Artificial Intelligence for Engineering Design, Analysis and Manufacturing, 28(4). 